Federal Reserve Bank of Dallas

Globalization and Monetary Policy Institute

Working Paper No. 207

https://www.dallasfed.org/ /media/documents/institute/wpapers/2014/0207.pdf

\title{
Can Interest Rate Factors Explain Exchange Rate Fluctuations?*
}

\author{
Julieta Yung \\ Federal Reserve Bank of Dallas
}

October 2014

Revised: March 2017

\begin{abstract}
This paper explores whether interest-rate risk priced in the yield curve drives foreign exchange movements for different country pairs. Using a dynamic term structure model under no arbitrage and complete markets, currency returns are modeled as the ratio of two countries' log stochastic discount factors. The implied risk premium establishes a non-linear relationship between interest rates and exchange rates that accounts for the failure of uncovered interest parity and compensates investors for the possible depreciation of the domestic currency. Interest rate factors explain about half of one-year exchange rate fluctuations for different countries during the 1980s-2016 period, suggesting that yield curves contain relevant information on exchange rate dynamics, and that this non-linear relationship is consistent with investors' behavior.
\end{abstract}

JEL codes: G15, F31, E43

\footnotetext{
* Julieta Yung, Federal Reserve Bank of Dallas, 2200 N. Pearl Street, Dallas, TX 75201. 214-922-5443. julieta.yung.@dal.frb.org. I am grateful to Tom Cosimano for his helpful comments and suggestions. I would also like to thank Tim Fuerst, Nelson Mark, Mark Wohar, and Jun Ma. This paper benefited from comments made by participants at the 2016 Systems Committee on International Economic Analysis Conference (Board of Governors) and the 2015 UBC Winter Finance Conference, especially Hanno Lustig. I also thank Tyler Atkinson for excellent research assistance and seminar participants at the Bank of England, DePaul University, University of Nebraska-Omaha, Miami University, Federal Reserve Bank of Dallas, Central Bank of Norway, Central Bank of Mexico (Financial Stability Division), ITAM School of Business, and University of Notre Dame (Economics Department and Mathematical Finance Research Group) for insightful comments. The views in this paper are those of the author and do not necessarily reflect the views of the Federal Reserve Bank of Dallas or the Federal Reserve System.
} 


\section{Introduction}

There is a strong theoretical connection between interest rates and exchange rates. This relationship is motivated by the idea that interest rates measure the amount of risk in the economy, and since that risk is priced in the yield curve, changes in bond risk premia reflect changes in the perception of risk, which should account (at least partially) for movements in other risk assets, such as the exchange rate. In the data, however, these links are less clear, giving rise to some of the most salient puzzles in international economics and finance, including the Uncovered Interest Parity (UIP) puzzle. UIP holds if currency depreciation compensates the investor for the interest rate differential across countries. The failure of UIP, as rationalized by Fama (1984), must be associated with differences in risk premia that allow investors to profit from carry trade strategies.

This paper explores whether interest rate factors can account for exchange rate fluctuations by allowing for non-linearities to govern the relationship between bond risk premia and currency returns in a two-country term structure framework. This is done by augmenting the no-arbitrage term structure model proposed by Joslin et al. (2011) and Joslin et al. (2013) to allow foreign and domestic factors to determine exchange rate dynamics at different horizons. I show that by allowing the model-implied risk premium to exhibit non-linearities, interest rate factors are able to account for up to half of the variation in one-year currency returns, above and beyond the interest rate differential implied by UIP.

The extension of a term structure model to an international context offers the opportunity to explore the failure of UIP in more detail. Specifically, I estimate the stochastic discount factors implied by the term structure of interest rates in two countries under no arbitrage. This framework allows a representative investor that has the opportunity to buy domestic and foreign assets, to use the same mechanism to price any other financial asset. Under complete markets across countries, the ratio of next period's exchange rate relative to the current level of the domestic price of one unit of the foreign currency is equal to the ratio of the foreign-to-domestic stochastic discount factors. This ratio includes the difference between the domestic and foreign interest rates, thus the interest rate differential explains only a small fraction of the movements in the exchange rate. This setup also allows for exchange rate fluctuations to depend on the risk premium component and the shocks to interest rate factors, which are amplified by the degree of risk aversion of investors. Thereby, in this paper I examine how the risk premium influences the path of the exchange rate, building from previous analysis of UIP that finds that currency risk premia estimated from term structure models satisfy the Fama conditions, such as in Frachot (1996), Backus et al. (2001), Brennan and Xia (2006), and Sarno et al. (2012).

The Gaussian stochastic discount factors yield a risk premium that is non-linear in the interest rate 
factors, is negatively correlated with the interest rate differential, and exhibits significantly higher volatility. Other papers have also identified the importance of non-linearities to account for exchange rate dynamics, such as Taylor et al. (2001), Clarida et al. (2003), Imbs et al. (2003), and Sarno et al. (2004). I find that the implied non-linearities in the risk premium allow the factors to have asymmetric effects on the exchange rate, as investors expect the domestic and foreign bond excess returns to revert back to their means. These properties are also consistent with optimal portfolio theory, since Chami et al. (2017) show that risk-averse investors experience capital gains when the factors approach the conditional mean of the stochastic discount factor and capital losses when they move further away. On that account, the empirical link between interest rates and exchange rates is strengthened through the presence of non-linearities in the risk premium that relate interest rates to exchange rates.

I capture interest rate risk by extracting three principal components from the yield curve of each country -the level, slope, and curvature of the term structures. Clarida and Taylor (1997) and Chen and Tsang (2013) find evidence that variables extracted from the yield curve, e.g., forward premium interest rate differentials, contain useful information for predicting exchange rates. ${ }^{1}$ Their results are also supported by the carry trade literature, which builds currency portfolios sorted by different foreign exchange and term structure variables, such as forward discounts, level and changes in interest rates, and the slope of the yield curve, to find common factors in currency returns; e.g. Ang and Chen (2010), Lustig et al. (2011), Lustig et al. (2014), Cenedese et al. (2014), Verdelhan (2015), Lustig et al. (2015). Those papers find common components that capture significant variation in exchange rates and are related to market volatility, uncertainty, or global macroeconomic risk. More importantly, their findings support the idea that exchange rate movements are explained by a set of common factors capturing economic risk. ${ }^{2}$

Through the international extension of a canonical no-arbitrage term structure model, non-linear risk premia accounts for a significant fraction of exchange rate fluctuations that is explained by domestic and foreign interest rate factors extracted from the yield curve. Results are in line with prior evidence of longhorizon predictability in risk assets, such as in stock returns (Fama and French, 1988), bond returns (Fama and Bliss, 1987), and exchange rates (Mark, 1995).

\footnotetext{
${ }^{1}$ Other papers, such as Inci and $\mathrm{Lu}(2004)$ and Yin and Li (2014), find that interest rates factors alone may be insufficient to determine exchange rate movements for particular country pairs and suggest incorporating unspanned macroeconomic variables to help explain exchange rate variation.

${ }^{2} \mathrm{My}$ paper also contributes to the rapidly growing literature that studies the joint dynamics of exchange rates and yield curves through term structure models. Some recent studies are Dong (2006), who develops a no-arbitrage two-country term structure model to explain exchange rate fluctuations between the U.S. and Germany; Benati (2006), who studies US/UK exchange rate fluctuations with unobservable factors; Chabi-Yo and Yang (2007), who introduce a New Keynesian model to study the Canadian dollar with macroeconomic variables; Diez de los Rios (2009) who develops a two-country term structure model where the exchange rate is determined by each country's risk-free rate; Pericoli and Taboga (2012), who use observable and unobservable variables to explore exchange rate dynamics with German data; and more recently, Bauer and Diez de los Rios (2012), who introduce a multi-country framework with interest rate, macroeconomic, and exchange rate variables.
} 


\section{Interest Rate Factors}

Let $Y_{t}$ be the set of $N$ interest rate factors that summarize a particular country's yield curve movements. The factors are extracted from a large set of yields at different maturities (from three months to ten years) by principal component analysis, i.e., the eigenvalue-eigenvector decomposition of the variance-covariance matrix of the yields. Hence, interest rate factors are observable variables constructed as $N$ linear combinations of zero-coupon yields, $y_{t}^{o b s}$, such that

$$
Y_{t}=W y_{t}^{o b s}
$$

where $W$ is an $(N \times M)$ matrix containing the weights or loadings that factors place on each maturity $m=\{1, \ldots, M\}$. Interest rate factors are uncorrelated by construction, have a mean of zero, and maximize variance among all directions orthogonal to the previous component.

It is customary in the literature to utilize the first three principal components to represent U.S. yields. Although more factors can be extracted, the first factor alone explains over 97 percent of the yield curve's cross-sectional variation during the 1983-2016 period, and the first three factors combined, account for more than 99 percent of these movements. ${ }^{3}$ This also holds true for all other countries considered and across different time periods. Summary statistics and figures can be found in the Data Appendix.

The factor loadings, $W$, exhibit similar patterns across countries: constant over maturity for the first factor (around 0.3), downward sloping for the second factor, and U-shaped for the third factor. Litterman and Scheinkman (1991) attributed the labels level, slope, and curvature to these three factors given the effect they have on the yield curve. For example, the first factor loads evenly across all yields, hence shocks to the first factor generate parallel shifts on the yield curve, changing the average or level of yields. The second factor loads positively on short-term maturities and negatively on long-term maturities, thus shocks move long and short yields in opposite directions, changing the slope of the yield curve. Finally, the third factor loads positively on short- and long-term maturities, but negatively on mid-range maturities, thus shocks to the third factor affect the concavity or curvature of yields. Litterman and Scheinkman's interpretation of the factors is also consistent with the geometric representation of the level as the average of all yields, the slope as the difference between the 3-month and 10-year yields, and the curvature as the difference between the sum of the 3-month and 10-year yields, and twice the 2-year yield.

The advantage of looking at interest rate factors is that one is able to relate movements in the entire yield curve, not just the short rate, to other risk assets, in this case the exchange rate. Therefore, in response to monetary policy tightening, for example, it is the average level, steepness, and concavity of the yield curve

\footnotetext{
${ }^{3}$ The first factor in each country captures most of the movement in yields, is the most persistent, and has higher standard deviation.
} 
that affects the path of the exchange rate, not just changes in the short rate. This allows for the risk priced in the cross-sectional variation of interest rates to contemporaneously determine exchange rate fluctuations. A disadvantage of focusing on interest rate factors, on the other hand, is that this relationship remains agnostic on how macroeconomic variables affect currency movements. ${ }^{4}$

\section{Two-Country Term Structure Framework}

I derive a two-country no-arbitrage dynamic term structure model in discrete time by extending the canonical setup developed by Joslin et al. (2011). ${ }^{5}$ While their original framework was developed to explain the crosssectional variation in U.S. yields, I propose a two-country extension that simultaneously accounts for both term structures of interest rates as well as movements in the exchange rate at different horizons under complete markets, as in Backus et al. (2001).

\subsection{Risk-Free Rates and No Arbitrage}

The one-period annualized risk-free rates for each country $\left(r_{t}, r_{t}^{*}\right)$ are linear in their corresponding set of factors as in Vasicek (1977),

$$
r_{t}=\rho_{0}+\rho_{1}^{\prime} Y_{t} \quad \text { and } \quad r_{t}^{*}=\rho_{0}^{*}+\rho_{1}^{*^{\prime}} Y_{t}^{*}
$$

where $\left(\rho_{0}, \rho_{0}^{*}\right)$ are $(1 \times 1)$ and $\left(\rho_{1}, \rho_{1}^{*}\right)$ are $(3 \times 1)$. Each country also has their own set of yields at different $m$ maturities $\left(y_{t, m}, y_{t, m}^{*}\right)$, which are linear in the factors as well,

$$
y_{t, m}=A_{m}+B_{m} Y_{t} \quad \text { and } \quad y_{t, m}^{*}=A_{m}^{*}+B_{m}^{*} Y_{t}^{*},
$$

where coefficients $\left(A_{m}, B_{m}\right)$ and $\left(A_{m}^{*}, B_{m}^{*}\right)$ satisfy internal consistency conditions. These cross-equation restrictions in the yield coefficients follow from the assumption that there are no arbitrage opportunities in

\footnotetext{
${ }^{4}$ It is debated in the literature whether macroeconomic risks are spanned by the yield curve and if macroeconomic variables have explanatory power over bond returns above and beyond the level, slope, and curvature. There is evidence that the level factor is highly correlated with aggregate supply shocks from the private sector (Wu, 2006) and shocks to preferences for current consumption and technology (Evans and Marshall, 2007), and the slope factor is related to monetary policy shocks (Evans and Marshall, 1998; Wu, 2006), since it disproportionally affects the short end of the yield curve. Joslin et al. (2014) suggest that some macroeconomic factors may have offsetting effects on the yield curve so that these macro-risk factors are not fully spanned by the level, slope, and curvature and should augment the interest rate factors to help predict yields under the physical measure. A recent discussion on this topic can be found in Bauer and Rudebusch (2016) and Bauer and Hamilton (2016). In this paper, I focus on the effects that interest rate factors have on currency returns and leave the examination of unspanned macroeconomic factors for future research.

${ }^{5}$ Term structure models originated with Vasicek (1977) in the finance literature, who presumed that the short-term interest rate was a linear function of a vector that followed a Gaussian diffusion (joint normal distribution). This has been the building block of a large family of term structure models, formalized by Duffie and Kan (1996), characterized by Dai and Singleton (2000, 2003), and expanded by many others. Joslin et al. (2011) proposed a framework with observable variables that yields fast-converging estimates by Maximum Likelihood. Surveys on the literature can be found in Diebold et al. (2005), Piazzesi and Schneider (2007), Piazzesi (2010), and Gürkaynak and Wright (2012). An excellent technical overview can be found in Singleton (2009).
} 
the local bond markets, as in Duffie and Kan (1996). This ensures that investors in each country receive the same risk-adjusted compensation for bonds of different maturities, and the yield curve is therefore consistent at each point in time.

\subsection{Bond Pricing and the Stochastic Discount Factor}

Let $P_{t, m}$ and $P_{t, m}^{*}$ be the prices at time $t$ of an $m$ maturity zero-coupon bond (no intermediate cash flows) in each country. Since asset prices are risk-adjusted expected values of their future payoffs,

$$
P_{t, m}=E_{t}^{\mathbb{P}}\left[M_{t+1} P_{t+1, m-1}\right] \quad \text { and } \quad P_{t, m}^{*}=E_{t}^{\mathbb{P}}\left[M_{t+1}^{*} P_{t+1, m-1}^{*}\right]
$$

where $M_{t+1}$ and $M_{t+1}^{*}$ are the stochastic discount factors (SDFs) - the pricing mechanisms that investors in each country develop in order to price assets in the local currency. The investors demand this risk premium to compensate for unaccounted fluctuations or uncertainty in the economy. ${ }^{6} \mathbb{P}$ represents the physical or actual process, such that $E_{t}^{\mathbb{P}}$ accounts for realized expectations of a historical process.

Let $\mathbb{Q}$ represent the risk-neutral process (guaranteed by the absence of arbitrage), such that asset prices can be expressed as expected values of their future payoffs discounted at the risk-free rate:

$$
P_{t, m}=e^{-r_{t}} E_{t}^{\mathbb{Q}}\left[P_{t+1, m-1}\right] \quad \text { and } \quad P_{t, m}^{*}=e^{-r_{t}^{*}} E_{t}^{\mathbb{Q}}\left[P_{t+1, m-1}^{*}\right]
$$

Equations (2) and (3) are equivalent representations of the asset pricing mechanism in each country. The evolution of each country's factors is therefore expressed under the two probability measures $\mathbb{P}$ and $\mathbb{Q}$ :

$$
\begin{gathered}
\Delta Y_{t}=K_{0}^{\mathbb{P}}+K_{1}^{\mathbb{P}} Y_{t-1}+\Sigma \epsilon_{t}^{\mathbb{P}} \quad \text { and } \quad \Delta Y_{t}^{*}=K_{0}^{\mathbb{P}, *}+K_{1}^{\mathbb{P}, *} Y_{t-1}^{*}+\Sigma^{*} \epsilon_{t}^{\mathbb{P}, *} \\
\Delta Y_{t}=K_{0}^{\mathbb{Q}}+K_{1}^{\mathbb{Q}} Y_{t-1}+\Sigma \epsilon_{t}^{\mathbb{Q}} \quad \text { and } \quad \Delta Y_{t}^{*}=K_{0}^{\mathbb{Q}, *}+K_{1}^{\mathbb{Q}, *} Y_{t-1}^{*}+\Sigma^{*} \epsilon_{t}^{\mathbb{Q}, *}
\end{gathered}
$$

Under $\mathbb{P}$ the factors move by an unrestricted vector auto-regressive (VAR) process that describes the evolution of the yields. Under $\mathbb{Q}$, its equivalent martingale measure, the process has already been adjusted for risk, allowing for a risk-neutral representation of the movement of factors over time. $\left(K_{0}^{\mathbb{P}}, K_{0}^{\mathbb{Q}}, K_{0}^{\mathbb{P}, *}, K_{0}^{\mathbb{Q}, *}\right)$ are $(3 \times 1)$ constant vectors that can be interpreted as the long-run average of the factors. $\left(K_{1}^{\mathbb{P}}, K_{1}^{\mathbb{Q}}, K_{1}^{\mathbb{P}, *}, K_{1}^{\mathbb{Q}, *}\right)$ are $(3 \times 3)$ matrices that account for the speed of mean reversion in the process towards their long-run mean. The shocks that disturb the state vector from moving back to its mean are i.i.d Gaussian, $\epsilon_{t}^{\mathbb{P}}, \epsilon_{t}^{\mathbb{Q}}, \epsilon_{t}^{\mathbb{P}, *}, \epsilon_{t}^{\mathbb{Q}, *} \sim$

\footnotetext{
${ }^{6}$ The SDF can be specifically linked to preferences through the marginal inter-temporal rate of substitution in a general equilibrium model. One of the advantages of specifying the SDF directly as a function of the state vector, is that it allows one to relate the risk premium to bonds across the yield curve without relying on assumptions about preferences and technology.
} 
$N\left(0, I_{N}\right) . \quad \Sigma$ and $\Sigma^{*}$ are lower triangular matrices such that $\Sigma \Sigma^{\prime}$ and $\Sigma^{*} \Sigma^{*^{\prime}}$ are the $(3 \times 3)$ variancecovariance matrices of innovations to $Y_{t}$ and $Y_{t}^{*}$.

The risk-free rate equations, together with the equations of motion for the factors under $\mathbb{P}$, help recover the historical moments of all bond returns in each country. The equations for the risk-free rate along with the equations of motion for the factors under $\mathbb{Q}$ price all the assets in the economy. The reason it is important to specify the distribution of the state variables under both measures, is because what lay between the $\mathbb{P}$ and $\mathbb{Q}$ distributions of the state vectors, equations (4) and (5), are adjustments for the market prices of risk: terms that capture agents' attitudes toward risk. As in Duffee (2002), the prices of risk are determined by the difference in the coefficients of the equations of motion,

$$
\begin{array}{lll}
\Lambda_{0}=K_{0}^{\mathbb{P}}-K_{0}^{\mathbb{Q}} & \text { and } & \Lambda_{0}^{*}=K_{0}^{\mathbb{P}, *}-K_{0}^{\mathbb{Q}, *}, \\
\Lambda_{1}=K_{1}^{\mathbb{P}}-K_{1}^{\mathbb{Q}} & \text { and } & \Lambda_{1}^{*}=K_{1}^{\mathbb{P}, *}-K_{1}^{\mathbb{Q}, *} .
\end{array}
$$

The price-of-risk coefficients measure how much the investor has to be compensated for fluctuations in the state vector. $\Lambda_{t}$ and $\Lambda_{t}^{*}$, the market prices of risk, take an affine functional form with respect to the factors,

$$
\Lambda_{t}=\Sigma^{-1}\left(\Lambda_{0}+\Lambda_{1} Y_{t}\right) \quad \text { and } \quad \Lambda_{t}^{*}=\Sigma^{*,-1}\left(\Lambda_{0}^{*}+\Lambda_{1}^{*} Y_{t}^{*}\right)
$$

which capture the prices of shocks to the risk factors per unit of volatility. Since they are independent of cash flow patterns of the securities being priced, they are common to all securities with payoffs that are functions of the factors, and are implied by the fact that factors are Gaussian under both distributions. $\Lambda_{0}, \Lambda_{0}^{*}$ represent the average prices of the factors assigned by investors, whereas $\Lambda_{1}, \Lambda_{1}^{*}$ measure how the market prices vary with respect to the risk factors summarized in $Y_{t}$ and $Y_{t}^{*}{ }^{7}$

The SDFs are then specified under the absence of arbitrage as exponential quadratic functions that depend on each country's set of factors through their risk-free rate and price-of-risk equations,

$$
M_{t+1}=\exp \left(-r_{t}-\frac{1}{2} \Lambda_{t}^{\prime} \Lambda_{t}-\Lambda_{t}^{\prime} \epsilon_{t+1}\right) \quad \text { and } \quad M_{t+1}^{*}=\exp \left(-r_{t}^{*}-\frac{1}{2} \Lambda_{t}^{*^{\prime}} \Lambda_{t}^{*}-\Lambda_{t}^{*^{\prime}} \epsilon_{t+1}^{*}\right)
$$

where $\epsilon_{t+1}, \epsilon_{t+1}^{*}$ are the vectors of shocks to the factors.

\footnotetext{
${ }^{7}$ Duffee (2002) and Dai and Singleton (2002) show that this equation is able to successfully match many features of the historical distribution of yields.
} 


\subsection{Modeling Exchange Rate Movements}

By no arbitrage and under complete markets, the exchange rate between two countries is governed by the ratio of their unique stochastic discount factors (Bekaert, 1996). Following Backus et al. (2001), let $S_{t}$ be the nominal spot exchange rate at time $t$; i.e., the domestic price of one unit of the foreign currency $*$, so that an increase in the exchange rate reflects the appreciation of the foreign currency. We thus have:

$$
\frac{S_{t+1}}{S_{t}}=\frac{M_{t+1}^{*}}{M_{t+1}}
$$

or, if extended to $k$ horizons (in months), the changes between time $t$ and $t+k$ are given by

$$
\frac{S_{t+k}}{S_{t}}=\frac{M_{t, t+k}^{*}}{M_{t, t+k}}
$$

where

$$
M_{t, t+k}=\prod_{j=1}^{k} M_{t+j} \quad \text { and } \quad M_{t, t+k}^{*}=\prod_{j=1}^{k} M_{t+j}^{*} .
$$

By taking logarithms, so that $\Delta s_{t, t+1}=\log \left(S_{t+1}\right)-\log \left(S_{t}\right)$, and by substituting equations (7) into (8), the one-month log exchange rate change can be expressed as

$$
\Delta s_{t, t+1}=\left(r_{t}-r_{t}^{*}\right)+\frac{1}{2}\left(\Lambda_{t}^{\prime} \Lambda_{t}-\Lambda_{t}^{*^{\prime}} \Lambda_{t}^{*}\right)+\left(\Lambda_{t}^{\prime} \epsilon_{t+1}-\Lambda_{t}^{*^{\prime}} \epsilon_{t+1}^{*}\right)
$$

and for $k$ horizon using equations (9) and (10),

$$
\begin{gathered}
\triangle s_{t, t+k}=I R D_{t, t+k}+R P_{t, t+k}+F S D_{t, t+k}, \\
I R D_{t, t+k} \equiv \sum_{j=1}^{k}\left(r_{t+j-1}-r_{t+j-1}^{*}\right), \\
R P_{t, t+k} \equiv \frac{1}{2} \sum_{j=1}^{k}\left(\Lambda_{t+j-1}^{\prime} \Lambda_{t+j-1}-\Lambda_{t+j-1}^{* \prime} \Lambda_{t+j-1}^{*}\right), \\
F S D_{t, t+k} \equiv \sum_{j=1}^{k}\left(\Lambda_{t+j-1}^{\prime} \epsilon_{t+j}-\Lambda_{t+j-1}^{* \prime} \epsilon_{t+j}^{*}\right) .
\end{gathered}
$$

This equation formally decomposes the depreciation rate into three different terms, which can be interpreted as the interest rate differential (IRD), the exchange rate risk premium (RP), and the difference in the shocks to the price of risk assigned by investors from each country or the factor shock differential (FSD).

The relationship between foreign exchange and the IRD is consistent with the uncovered interest parity 
condition, which relates depreciation rates to the relative interest rates between countries. Given that riskfree rates are linear functions of the factors $Y_{t}$ and $Y_{t}^{*}$ from equations (1), currency movements are linearly determined by the interest rate factors through this term.

The exchange rate is also determined by the RP, half the difference in the spread of the conditional variances of the domestic and foreign SDFs. The presence of this component suggests that unless the conditional variances of both countries' SDFs are identical, the uncovered interest parity condition does not hold. If the domestic country's SDF is more volatile than its foreign counterpart, a higher exchange rate risk premium compensates domestic investors for the depreciation of the domestic currency, and vice-versa. Moreover, the RP relates interest rate factors to the exchange rate non-linearly through the price-of-risk equations (6). ${ }^{8}$ This relationship departs from the standard approach in which excess returns are linearly projected onto economic fundamentals. As it is known in the literature, the relationship between log exchange rate movements and interest rate factors is not well captured by linear regressions.

The FSD term, which accounts for the conditional volatility of the depreciation rate, is comprised of the relative innovations to the interest rate factors, amplified by their respective market prices of risk. This suggests that shocks to the yield curve also have the potential to affect exchange rate movements through this final component.

The domestic (foreign) SDF reflects the fluctuations in the domestic (foreign) factors implied by the country's yield curve. However, both domestic and foreign factors have the potential to influence the path of the exchange rate linearly through the IRD and FSD components and non-linearly though the RP. The contribution of each term to explaining currency fluctuations and the role of the RP in accounting for deviations to the uncovered interest parity condition are further explored in the context of Fama (1984) and Backus et al. (2001).

\section{Estimation: Maximum Likelihood}

The parameters to be estimated are $\Theta=\left\{K_{0}^{\mathbb{P}}, K_{1}^{\mathbb{P}}, \Sigma, K_{0}^{\mathbb{Q}}, K_{1}^{\mathbb{Q}}, \rho_{0}, \rho_{1}, K_{0}^{\mathbb{P}, *}, K_{1}^{\mathbb{P}, *}, \Sigma^{*}, K_{0}^{\mathbb{Q}, *}, K_{1}^{\mathbb{Q}, *}, \rho_{0}^{*}, \rho_{1}^{*}\right\}$. Joslin et al. (2011) show that parameters can be rotated through invariant transformations so that the new vector of parameters to be estimated can be summarized by: $\tilde{\Theta}=\left\{K_{0}^{\mathbb{P}}, K_{1}^{\mathbb{P}}, \Sigma, \lambda^{\mathbb{Q}}, K_{0}^{\mathbb{P}, *}, K_{1}^{\mathbb{P}, *}, \Sigma^{*}, \lambda^{\mathbb{Q}, *}\right\} .{ }^{9}$ The parameters $\left(K_{0}^{\mathbb{P}}, K_{1}^{\mathbb{P}}, K_{0}^{\mathbb{P}, *}, K_{1}^{\mathbb{P}, *}\right)$ that maximize the log likelihood function $f(\cdot)$ conditional on $t=$ 0 information are given by the OLS estimates of the conditional means of $Y_{t}$ and $Y_{t}^{*} . \quad \Sigma$ and $\Sigma^{*}$ are

\footnotetext{
${ }^{8}$ This specification for exchange rates also yields a time-varying exchange rate RP, which is consistent with earlier findings from Campbell and Shiller (1991) and Backus et al. (2001), among others, that provide evidence from yield and forward rate regressions for a time-varying risk premium. Time-variance is also important to match the dynamics of yields in the data and deviations from the Expectations Hypothesis, as shown in Dai and Singleton (2002).

${ }^{9}$ Refer to the Appendix for details on the parameter rotation.
} 
parameterized by the lower triangular Cholesky factorization of the variance-covariance matrix from the vector auto-regressions under $Y_{t}$ and $Y_{t}^{*}$ for both countries, as suggested by Joslin et al. (2013). $\lambda^{\mathbb{Q}}$ and $\lambda^{\mathbb{Q}, *}$ are vectors of ordered eigenvalues in the $K_{1}^{\mathbb{Q}}$ and $K_{1}^{\mathbb{Q}, *}$ matrices. They can be interpreted as the speed of mean reversion of the factors under risk-neutrality and are assumed to be real, parameterized by the difference in ordered eigenvalues. The model is $\mathbb{Q}$ stationary because the difference in eigenvalues is negative by construction.

The conditional log likelihood function can then be factorized into the risk-neutral and the physical conditional densities of the observed data:

$$
f\left(z_{t}^{o b s} \mid z_{t-1}^{o b s} ; \tilde{\Theta}\right)=f^{\mathbb{Q}}\left(z_{t}^{o b s} \mid \bar{Y}_{t}\right)+f^{\mathbb{P}}\left(\bar{Y}_{t} \mid \bar{Y}_{t-1}\right)
$$

where $z_{t}^{o b s}$ is the vector of observed data: $z_{t}^{o b s}=\left[\begin{array}{lll}y_{t}^{o b s} & y_{t}^{o b s, *} & \Delta s_{t}^{o b s}\end{array}\right]^{\prime}$ and the interest rate factors are $\bar{Y}=\left[\begin{array}{cc}Y_{t} & Y_{t}^{*}\end{array}\right]^{\prime}$. The $\mathbb{P}$ conditional density of the observed vector captures the time-series properties of the factors, whereas the $\mathbb{Q}$ conditional density captures the cross-sectional properties of the data.

Under the assumption that $Y_{t}$ and $Y_{t}^{*}$ are conditionally Gaussian, the log likelihood under $\mathbb{P}$ can be expressed as

$$
f^{\mathbb{P}}\left(\bar{Y}_{t} \mid \bar{Y}_{t-1}\right)=\frac{\bar{N}}{2} \cdot \log (2 \pi)+\frac{1}{2} \cdot \log \left|\Sigma^{\prime} \Sigma\right|+\frac{1}{2} \sum_{t=1}^{T}\left(\left(\bar{Y}_{t}-E_{t-1}\left[\bar{Y}_{t}\right]\right) \cdot\left(\Sigma^{\prime} \Sigma\right)^{-1} \cdot\left(\bar{Y}_{t}-E_{t-1}\left[\bar{Y}_{t}\right]\right)\right)
$$

where $T$ is the total number of time observations, $\bar{N}=6$ is the total number of domestic and foreign factors in the model and $\Sigma^{\prime} \Sigma=\left[\begin{array}{cc}\Sigma^{\prime} \Sigma & 0 \\ 0 & \Sigma^{*^{\prime}} \Sigma^{*}\end{array}\right]$. When the off-diagonal elements are zero, there are no crosscountry effects in the variance-covariance matrix. This assumption is later relaxed in the Appendix to allow for cross-country effects, which does not change the baseline results.

The log likelihood under $\mathbb{Q}$ can be expressed as

$$
f^{\mathbb{Q}}\left(z_{t}^{o b s} \mid \bar{Y}_{t}\right)=\frac{1}{2} \sum_{t=1}^{T} e_{t}^{2} / \Sigma_{e}^{2}+\frac{1}{2}(\bar{J}-\bar{N}) \cdot \log (2 \pi)+\frac{1}{2}(\bar{J}-\bar{N}) \cdot \log \left(\Sigma_{e}^{2}\right),
$$

where $e_{t}^{2}$ is the vector with square deviations between the observed data and the model-implied yields and exchange rates, for

$$
e_{t}=\left[\begin{array}{c}
e_{t}^{y} \\
e_{t}^{y, *} \\
e_{t}^{\Delta s}
\end{array}\right]=\left[\begin{array}{c}
y_{t}^{o b s}-y_{t} \\
y_{t}^{o b s, *}-y_{t}^{*} \\
\Delta s_{t}^{o b s}-\Delta s_{t}
\end{array}\right]
$$


The errors are conditionally independent of their lagged values and satisfy consistency conditions as specified in Joslin et al. (2011). Finally, $\Sigma_{e}=\sqrt{\frac{\sum_{t=1}^{T} e_{t}^{2}}{T(\bar{J}-\bar{N})}}$, where $\bar{J}$ is the number of total observed variables.

\subsection{Data}

Exchange rate data are from Bloomberg L.P. and in logs. Interest rate factors are extracted from monthly yield curve data obtained from various sources. Table 1 summarizes the sample considered for every country along with the yield curve data sources utilized. All zero-coupon yields, from three months to ten years are in percentage, end-of-month, annualized, and in local currency. Specific source details, figures, and summary statistics can be found in the Data Appendix.

Table 1: Yield Curve Data Sources

\begin{tabular}{|c|c|c|}
\hline & sample & sources \\
\hline Australia & 1983.01-2016.01 & $\begin{array}{l}\text { Reserve Bank of Australia; Global Financial Database; Haver/OECD; } \\
\text { Bloomberg L.P.; author's calculations. }\end{array}$ \\
\hline Canada & 1990.01-2016.01 & Bank of Canada. \\
\hline Japan & $1985.01-2016.01$ & Ministry of Finance; Haver/IFS; Bloomberg L.P.; author's calculations. \\
\hline Norway & $1990.01-2016.01$ & Global Financial Dataset; Bloomberg L.P.; author's calculations. \\
\hline Sweden & $1984.02-2016.01$ & Riksbank; Bloomberg L.P.; BIS; Haver/IFS; author's calculations. \\
\hline Switzerland & 1988.01-2016.01 & Swiss National Bank; Bloomberg L.P.; Haver/OECD; author's calculations. \\
\hline United Kingdom & 1986.01-2016.01 & Bank of England; author's calculations. \\
\hline United States & $1983.01-2016.01$ & Board of Governors; author's calculations. \\
\hline
\end{tabular}

The baseline two-country model with three factors for each country -level, slope, and curvature, has the U.S. as the domestic country and the log exchange rate changes are expressed in USD. The foreign country $(*)$ is either Australia, Canada, Japan, Norway, Sweden, Switzerland, or the U.K., and the sample period considered varies according to yield-curve data availability for the foreign country.

\subsection{Parameter Estimates}

Table 2 presents the $K_{0}^{\mathbb{P}},\left(K_{1}^{\mathbb{P}}+I\right)$, and $\Sigma$ estimates for factor dynamics under $\mathbb{P}$ from equations (4) for the U.S. and its foreign counterpart. All parameters are annualized and the corresponding asymptotic standard errors are in parentheses. The diagonal elements of the $\left(K_{1}^{\mathbb{P}}+I\right)$ matrix are close to one and statistically significant at the 99 percent level, capturing the fact that interest rate factors are very persistent. In general, the first-order autocorrelation parameter for the first factor is around 0.99, the second is between 0.92 and 0.97 , and the third one ranges from 0.75 to 0.93 . The off-diagonal elements tend to be small and statistically insignificant.

$\Sigma$ represents the lower triangular Cholesky factorization of the variance-covariance matrix of the innovations to the factors, which contains large, positive, and statistically significant diagonal elements. These 
estimates serve as a good initial guess for the parameters obtained under Maximum Likelihood, $\Sigma^{M L}$, as suggested by Joslin et al. (2013). Details on the estimation and risk-neutral parameters can also be found in the Appendix.

Table 2: $\quad$ Physical Distribution Parameters of Term Structure Model

\begin{tabular}{|c|c|c|c|c|c|c|c|c|c|c|c|c|c|c|c|}
\hline \multirow{2}{*}{$\begin{array}{l}\text { Parameters: } \\
\text { AUS }\end{array}$} & \multirow{2}{*}{$\begin{array}{c}K_{0}^{\mathbb{P}} \\
0.01\end{array}$} & \multirow{2}{*}{$\begin{array}{c}\text { (S.E.) } \\
(0.18)\end{array}$} & \multicolumn{5}{|c|}{$K_{1}^{\mathbb{P}}+I$ (S.E.) } & \multicolumn{7}{|c|}{$\Sigma($ S.E. $)$} & \multirow{3}{*}{$\begin{array}{c}\text { Sample } \\
\text { Jan-1983 } \\
\text { Jan-2016 }\end{array}$} \\
\hline & & & 0.996 & $(0.00)$ & -0.04 & $(0.04)$ & -0.27 & $(0.14)$ & 1.29 & $(0.05)$ & & & & & \\
\hline & -0.03 & $(0.07)$ & 0.00 & $(0.00)$ & 0.96 & $(0.01)$ & -0.30 & $(0.05)$ & -0.02 & $(0.62)$ & 0.49 & $(0.19)$ & & & \\
\hline & 0.06 & $(0.04)$ & 0.00 & $(0.00)$ & 0.00 & $(0.01)$ & 0.75 & $(0.03)$ & -0.14 & $(0.04)$ & 0.07 & $(0.15)$ & 0.26 & $(0.04)$ & \\
\hline \multirow[t]{3}{*}{ US } & 0.28 & $(0.21)$ & 0.994 & $(0.00)$ & 0.01 & $(0.03)$ & -0.21 & $(0.16)$ & 0.94 & $(0.29)$ & & & & & \\
\hline & 0.13 & $(0.08)$ & 0.00 & $(0.00)$ & 0.97 & $(0.01)$ & -0.24 & $(0.06)$ & -0.15 & $(0.22)$ & 0.32 & $(0.05)$ & & & \\
\hline & 0.15 & $(0.04)$ & 0.00 & $(0.00)$ & 0.00 & $(0.01)$ & 0.84 & $(0.03)$ & -0.06 & $(0.22)$ & 0.01 & $(0.06)$ & 0.15 & $(0.04)$ & \\
\hline \multirow[t]{3}{*}{ CAN } & 0.07 & $(0.17)$ & 0.989 & $(0.01)$ & -0.00 & $(0.04)$ & -0.03 & $(0.15)$ & 0.95 & $(0.07)$ & & & & & Jan-1990 \\
\hline & 0.07 & $(0.07)$ & -0.00 & $(0.00)$ & 0.95 & $(0.02)$ & -0.24 & $(0.06)$ & 0.02 & $(0.03)$ & 0.40 & $(0.01)$ & & & Jan-2016 \\
\hline & 0.09 & $(0.03)$ & 0.00 & $(0.00)$ & 0.00 & $(0.01)$ & 0.84 & $(0.03)$ & -0.09 & $(0.02)$ & 0.04 & $(0.02)$ & 0.17 & $(0.01)$ & \\
\hline \multirow[t]{3}{*}{ US } & 0.57 & $(0.21)$ & 0.990 & $(0.01)$ & 0.02 & $(0.03)$ & -0.42 & $(0.14)$ & 0.78 & $(0.13)$ & & & & & \\
\hline & 0.16 & $(0.09)$ & 0.00 & $(0.00)$ & 0.97 & $(0.01)$ & -0.26 & $(0.07)$ & -0.21 & $(0.02)$ & 0.29 & $(0.01)$ & & & \\
\hline & 0.14 & $(0.04)$ & 0.00 & $(0.00)$ & 0.00 & $(0.01)$ & 0.85 & $(0.03)$ & -0.07 & $(0.03)$ & -0.02 & $(0.01)$ & 0.14 & $(0.01)$ & \\
\hline \multirow[t]{3}{*}{ JAP } & 0.16 & $(0.09)$ & 0.993 & $(0.00)$ & 0.07 & $(0.04)$ & -0.17 & $(0.14)$ & 0.63 & $(0.29)$ & & & & & Jan-1985 \\
\hline & 0.01 & $(0.03)$ & 0.00 & $(0.00)$ & 0.97 & $(0.01)$ & -0.16 & $(0.05)$ & -0.12 & $(0.07)$ & 0.20 & $(0.03)$ & & & Jan-2016 \\
\hline & 0.06 & $(0.02)$ & 0.00 & $(0.00)$ & -0.00 & $(0.01)$ & 0.75 & $(0.03)$ & -0.10 & $(0.10)$ & -0.02 & $(0.02)$ & 0.12 & $(0.01)$ & \\
\hline \multirow[t]{3}{*}{ US } & 0.47 & $(0.21)$ & 0.991 & $(0.01)$ & 0.02 & $(0.03)$ & -0.32 & $(0.15)$ & 0.89 & $(0.26)$ & & & & & \\
\hline & 0.09 & $(0.08)$ & 0.00 & $(0.00)$ & 0.97 & $(0.01)$ & -0.21 & $(0.06)$ & -0.18 & $(0.16)$ & 0.30 & $(0.02)$ & & & \\
\hline & 0.14 & $(0.04)$ & 0.00 & $(0.00)$ & 0.00 & $(0.01)$ & 0.85 & $(0.03)$ & -0.06 & $(0.13)$ & -0.00 & $(0.03)$ & 0.15 & $(0.02)$ & \\
\hline \multirow[t]{3}{*}{ NOR } & 0.13 & $(0.15)$ & 0.991 & $(0.01)$ & -0.08 & $(0.03)$ & -0.37 & $(0.11)$ & 0.91 & $(0.05)$ & & & & & Jan-1990 \\
\hline & 0.00 & $(0.08)$ & 0.00 & $(0.00)$ & 0.94 & $(0.02)$ & -0.20 & $(0.06)$ & 0.06 & $(0.10)$ & 0.50 & $(0.04)$ & & & Jan-2016 \\
\hline & 0.10 & $(0.04)$ & 0.00 & $(0.00)$ & -0.00 & $(0.01)$ & 0.80 & $(0.03)$ & -0.03 & $(0.09)$ & 0.07 & $(0.06)$ & 0.26 & $(0.05)$ & \\
\hline \multirow[t]{3}{*}{ US } & 0.57 & $(0.21)$ & 0.990 & $(0.01)$ & 0.02 & $(0.03)$ & -0.42 & $(0.14)$ & 0.78 & $(0.05)$ & & & & & \\
\hline & 0.16 & $(0.09)$ & 0.00 & $(0.00)$ & 0.97 & $(0.01)$ & -0.26 & $(0.07)$ & -0.21 & $(0.10)$ & 0.29 & $(0.13)$ & & & \\
\hline & 0.14 & $(0.04)$ & 0.00 & $(0.00)$ & 0.00 & $(0.01)$ & 0.85 & $(0.03)$ & -0.07 & $(0.06)$ & -0.02 & $(0.09)$ & 0.14 & $(0.01)$ & \\
\hline \multirow[t]{3}{*}{ SWE } & 0.10 & $(0.16)$ & 0.998 & $(0.00)$ & -0.08 & $(0.04)$ & 0.46 & $(0.13)$ & 1.08 & $(0.02)$ & & & & & Feb-1984 \\
\hline & 0.01 & $(0.09)$ & 0.00 & $(0.00)$ & 0.92 & $(0.02)$ & 0.28 & $(0.07)$ & 0.07 & $(0.02)$ & 0.58 & $(0.02)$ & & & Dec-2015 \\
\hline & -0.09 & $(0.03)$ & -0.00 & $(0.00)$ & 0.01 & $(0.01)$ & 0.85 & $(0.03)$ & -0.01 & $(0.01)$ & -0.10 & $(0.01)$ & 0.21 & $(0.01)$ & \\
\hline \multirow[t]{3}{*}{ US } & 0.38 & $(0.21)$ & 0.991 & $(0.01)$ & 0.02 & $(0.03)$ & -0.25 & $(0.16)$ & 0.93 & $(0.03)$ & & & & & \\
\hline & 0.12 & $(0.08)$ & 0.00 & $(0.00)$ & 0.97 & $(0.01)$ & -0.23 & $(0.06)$ & -0.16 & $(0.02)$ & 0.32 & $(0.03)$ & & & \\
\hline & 0.15 & $(0.04)$ & 0.00 & $(0.00)$ & 0.00 & $(0.01)$ & 0.84 & $(0.03)$ & -0.06 & $(0.01)$ & 0.00 & $(0.01)$ & 0.15 & $(0.01)$ & \\
\hline \multirow[t]{3}{*}{ SWI } & 0.19 & $(0.11)$ & 0.999 & $(0.00)$ & 0.03 & $(0.03)$ & 0.26 & $(0.10)$ & 0.63 & $(0.41)$ & & & & & Jan-1988 \\
\hline & 0.06 & $(0.05)$ & -0.00 & $(0.00)$ & 0.96 & $(0.01)$ & 0.16 & $(0.05)$ & 0.01 & $(0.26)$ & 0.32 & $(0.02)$ & & & Dec-2015 \\
\hline & -0.08 & $(0.03)$ & -0.00 & $(0.00)$ & 0.01 & $(0.01)$ & 0.83 & $(0.03)$ & 0.02 & $(0.15)$ & -0.06 & $(0.01)$ & 0.16 & $(0.01)$ & \\
\hline \multirow[t]{3}{*}{ US } & 0.38 & $(0.20)$ & 0.995 & $(0.01)$ & 0.01 & $(0.03)$ & -0.32 & $(0.14)$ & 0.81 & $(0.48)$ & & & & & \\
\hline & 0.10 & $(0.09)$ & 0.00 & $(0.00)$ & 0.97 & $(0.01)$ & -0.23 & $(0.06)$ & -0.19 & $(0.12)$ & 0.30 & $(0.03)$ & & & \\
\hline & 0.14 & $(0.04)$ & 0.00 & $(0.00)$ & 0.00 & $(0.01)$ & 0.86 & $(0.03)$ & -0.07 & $(0.06)$ & -0.01 & $(0.02)$ & 0.14 & $(0.01)$ & \\
\hline \multirow[t]{3}{*}{ UK } & 0.08 & $(0.14)$ & 0.995 & $(0.00)$ & 0.03 & $(0.03)$ & -0.02 & $(0.09)$ & 0.84 & $(0.07)$ & & & & & Jan-1989 \\
\hline & -0.04 & $(0.07)$ & -0.00 & $(0.00)$ & 0.97 & $(0.01)$ & -0.05 & $(0.04)$ & -0.14 & $(0.31)$ & 0.37 & $(0.11)$ & & & Jan-2016 \\
\hline & 0.04 & $(0.03)$ & 0.00 & $(0.00)$ & 0.00 & $(0.01)$ & 0.93 & $(0.02)$ & -0.09 & $(0.27)$ & -0.02 & $(0.17)$ & 0.16 & $(0.03)$ & \\
\hline \multirow[t]{3}{*}{ US } & 0.52 & $(0.21)$ & 0.990 & $(0.01)$ & 0.02 & $(0.03)$ & -0.37 & $(0.14)$ & 0.80 & $(0.33)$ & & & & & \\
\hline & 0.12 & $(0.09)$ & 0.00 & $(0.00)$ & 0.97 & $(0.01)$ & -0.24 & $(0.06)$ & -0.21 & $(0.40)$ & 0.29 & $(0.03)$ & & & \\
\hline & 0.13 & $(0.04)$ & 0.00 & $(0.00)$ & 0.00 & $(0.01)$ & 0.86 & $(0.03)$ & -0.08 & $(0.15)$ & -0.02 & $(0.04)$ & 0.14 & $(0.02)$ & \\
\hline
\end{tabular}

Notes: Parameters represent factor dynamics under the physical distribution, where $\Delta Y_{t+1}=K_{0}^{\mathbb{P}}+K_{1}^{\mathbb{P}} Y_{t}+\Sigma \epsilon_{t+1}^{\mathbb{P}}$ with asymptotic standard errors in parentheses. All parameters are annualized and $K_{0}^{\mathbb{P}}$ and $\Sigma$ are $\times 100$. 


\section{Results}

This section summarizes the overall fit of the model for each country pair. The U.K./U.S. model results are displayed to allow for a more in-depth discussion, and figures for all other countries along with other goodness-of-fit measures can be found in the Appendix, Section C. Robustness checks are further discussed in Section 6.

\subsection{Yield Curve Fit}

Each two-country model is estimated separately. Figures 1 and 2 show the yield curve fit relative to the data for the U.S. and the U.K. during the 1986-2016 period. In most cases, the model is indistinguishable from the data, indicating that the three factors are successful at matching the yields of their respective countries simultaneously, while also fitting the exchange rate. There are, nonetheless, times when the model deviates from the data. For example, when fitting the U.K. ten-year yield in figure 1, the largest yield-curve fitting errors occur between the mid 1990s and the early 2000s. These fitting errors arise as the model seeks parameters that can maximize the fit of both yield curves and the exchange rate throughout the entire sample, which generates a trade-off that is further explored in this section. Although term structure models are built to fit yield curves, figures 1 and 2 suggest that the canonical domestic model can be extended to an international setting and still successfully fit the yield curves of both countries simultaneously. This is true even when considering extended time periods with very different interest rate dynamics, including structural breaks and the zero lower bound. Other models, of course, would be better suited to perfectly match the yield curves if the intention were to highlight investment opportunities that arise from deviations from the zero-coupon yield curves, or rigorously study the yield curve properties of a particular country.

As a general measure of yield-curve fit, table 3 presents the mean, standard deviation, and first-order autocorrelation of the data and the model-implied yields for short-, mid-, and long-term maturities of every country. The model is able to match different moments in the data for all maturities and all countries and the null hypothesis that the sample moments are identical to the data cannot be rejected. Moreover, the projection of the data onto the corresponding model-implied yield generates $R^{2}$ higher that 0.99 with root mean squared errors (RMSEs) well below half a percentage point, as can be seen in the Appendix.

\subsection{Exchange Rate Fit}

The results for the GBP/USD log exchange rate changes at different horizons are shown in figure 3. The model is able to generate enough variation to capture exchange rate movements on average relatively well, particularly as the horizon increases. These results are in line with the literature that finds that very 
short exchange rate fluctuations are quite difficult to predict (Meese and Rogoff (1983) find that the best forecasting model is obtained under the assumption that the exchange rate follows a random walk), but at longer horizons the predictability of exchange rates improves (Mark, 1995).

Table 3: Yields Sample Moments

\begin{tabular}{|c|c|c|c|c|c|c|c|c|c|c|}
\hline & & \multicolumn{3}{|c|}{ Mean } & \multicolumn{3}{|c|}{ Standard Deviation } & \multicolumn{3}{|c|}{ First Order Autocorrelation } \\
\hline & & 3-month & 3-year & 10-year & 3-month & 3-year & 10-year & 3-month & 3-year & 10-year \\
\hline \multirow[t]{3}{*}{ AUS } & Model & 7.288 & 7.340 & 7.856 & 4.612 & 3.828 & 3.145 & 0.988 & 0.986 & 0.991 \\
\hline & Data & 7.393 & 7.461 & 7.925 & 4.448 & 3.819 & 3.544 & 0.989 & 0.987 & 0.990 \\
\hline & pval: model $=$ data & 0.746 & 0.658 & 0.772 & 0.470 & 0.964 & 0.018 & 0.586 & 0.556 & 0.476 \\
\hline \multirow[t]{3}{*}{ US } & Model & 4.231 & 5.041 & 6.181 & 2.939 & 3.024 & 2.529 & 0.992 & 0.988 & 0.986 \\
\hline & Data & 4.079 & 4.896 & 5.995 & 2.883 & 3.031 & 2.616 & 0.992 & 0.988 & 0.986 \\
\hline & pval: model=data & 0.462 & 0.500 & 0.309 & 0.699 & 0.964 & 0.502 & 0.701 & 0.383 & 0.619 \\
\hline \multirow[t]{3}{*}{ CAN } & Model & 3.751 & 4.391 & 5.245 & 2.805 & 2.599 & 2.405 & 0.973 & 0.980 & 0.988 \\
\hline & Data & 3.759 & 4.396 & 5.250 & 2.817 & 2.604 & 2.401 & 0.973 & 0.980 & 0.988 \\
\hline & pval: model $=$ data & 0.970 & 0.982 & 0.980 & 0.943 & 0.976 & 0.974 & 0.557 & 0.841 & 0.966 \\
\hline \multirow[t]{3}{*}{ US } & Model & 3.078 & 3.792 & 4.996 & 2.358 & 2.285 & 1.791 & 0.987 & 0.982 & 0.979 \\
\hline & Data & 3.094 & 3.803 & 5.012 & 2.321 & 2.290 & 1.841 & 0.987 & 0.983 & 0.979 \\
\hline & pval: model=data & 0.933 & 0.951 & 0.912 & 0.779 & 0.968 & 0.633 & 0.967 & 0.794 & 0.850 \\
\hline \multirow[t]{3}{*}{ JAP } & Model & 1.742 & 1.957 & 2.789 & 2.376 & 2.208 & 2.035 & 0.992 & 0.986 & 0.987 \\
\hline & Data & 1.692 & 1.906 & 2.755 & 2.377 & 2.217 & 2.022 & 0.992 & 0.986 & 0.987 \\
\hline & pval: model=data & 0.775 & 0.753 & 0.816 & 0.996 & 0.937 & 0.901 & 0.661 & 0.966 & 0.965 \\
\hline \multirow[t]{3}{*}{ US } & Model & 3.804 & 4.541 & 5.668 & 2.712 & 2.683 & 2.127 & 0.991 & 0.984 & 0.981 \\
\hline & Data & 3.738 & 4.501 & 5.631 & 2.622 & 2.670 & 2.243 & 0.990 & 0.984 & 0.981 \\
\hline & pval: model $=$ data & 0.736 & 0.839 & 0.815 & 0.513 & 0.926 & 0.305 & 0.711 & 0.819 & 0.823 \\
\hline \multirow[t]{3}{*}{ NOR } & Model & 4.782 & 4.864 & 5.444 & 3.280 & 2.816 & 2.223 & 0.976 & 0.985 & 0.986 \\
\hline & Data & 4.784 & 4.879 & 5.437 & 3.098 & 2.756 & 2.425 & 0.974 & 0.981 & 0.987 \\
\hline & pval: model $=$ data & 0.992 & 0.946 & 0.971 & 0.314 & 0.702 & 0.125 & 0.272 & 0.162 & 0.539 \\
\hline \multirow[t]{3}{*}{ US } & Model & 3.099 & 3.805 & 5.015 & 2.338 & 2.267 & 1.850 & 0.987 & 0.981 & 0.984 \\
\hline & Data & 3.094 & 3.803 & 5.012 & 2.321 & 2.290 & 1.841 & 0.987 & 0.980 & 0.984 \\
\hline & pval: model=data & 0.981 & 0.989 & 0.985 & 0.893 & 0.857 & 0.928 & 0.931 & 0.078 & 0.432 \\
\hline \multirow[t]{3}{*}{ SWE } & Model & 5.616 & 6.097 & 6.649 & 4.559 & 4.207 & 3.686 & 0.985 & 0.994 & 0.994 \\
\hline & Data & 5.622 & 6.100 & 6.645 & 4.449 & 4.204 & 3.804 & 0.985 & 0.994 & 0.993 \\
\hline & pval: model=data & 0.987 & 0.992 & 0.987 & 0.633 & 0.987 & 0.539 & 0.954 & 0.768 & 0.547 \\
\hline \multirow[t]{3}{*}{ US } & Model & 3.923 & 4.719 & 5.828 & 2.823 & 2.895 & 2.445 & 0.989 & 0.984 & 0.981 \\
\hline & Data & 3.924 & 4.719 & 5.831 & 2.784 & 2.898 & 2.473 & 0.989 & 0.984 & 0.982 \\
\hline & pval: model=data & 0.997 & 1.000 & 0.987 & 0.788 & 0.984 & 0.827 & 0.817 & 0.880 & 0.610 \\
\hline \multirow[t]{3}{*}{ SWI } & Model & 2.403 & 2.572 & 3.286 & 2.624 & 2.110 & 1.714 & 0.987 & 0.994 & 0.995 \\
\hline & Data & 2.374 & 2.535 & 3.242 & 2.536 & 2.091 & 1.735 & 0.988 & 0.994 & 0.995 \\
\hline & pval: model=data & 0.887 & 0.820 & 0.744 & 0.532 & 0.869 & 0.825 & 0.325 & 0.611 & 0.964 \\
\hline \multirow[t]{3}{*}{ US } & Model & 3.466 & 4.157 & 5.313 & 2.585 & 2.482 & 1.951 & 0.993 & 0.987 & 0.983 \\
\hline & Data & 3.436 & 4.128 & 5.280 & 2.552 & 2.489 & 2.004 & 0.993 & 0.986 & 0.983 \\
\hline & pval: model $=$ data & 0.880 & 0.880 & 0.829 & 0.815 & 0.963 & 0.623 & 0.772 & 0.555 & 0.764 \\
\hline \multirow[t]{3}{*}{ UK } & Model & 4.794 & 5.091 & 5.401 & 3.648 & 3.103 & 2.580 & 0.991 & 0.991 & 0.990 \\
\hline & Data & 4.892 & 5.072 & 5.562 & 3.675 & 3.098 & 2.540 & 0.991 & 0.990 & 0.990 \\
\hline & pval: model $=$ data & 0.732 & 0.940 & 0.423 & 0.894 & 0.974 & 0.778 & 0.642 & 0.777 & 0.998 \\
\hline \multirow[t]{3}{*}{ US } & Model & 3.334 & 3.991 & 5.143 & 2.542 & 2.410 & 1.833 & 0.989 & 0.983 & 0.981 \\
\hline & Data & 3.292 & 3.971 & 5.136 & 2.494 & 2.409 & 1.916 & 0.988 & 0.982 & 0.981 \\
\hline & pval: model=data & 0.833 & 0.917 & 0.961 & 0.733 & 0.994 & 0.425 & 0.421 & 0.427 & 0.613 \\
\hline
\end{tabular}

Notes: "p-val: model=data" is the p-value of (1) a two-sample $t$-test for the null hypothesis that the data and the model-implied yields come from independent random samples from normal distributions with equal mean but unknown variances; (2) a two-sample $F$-test for the null hypothesis that the data and the model-implied yields come from normal distributions with the same variance; and (3) a $\chi^{2}$-test for the null hypothesis that the first-order autocorrelation coefficients from the data and the model-implied yields (estimated jointly using Seemingly Unrelated Regression) are the same, based on an asymptotic normal distribution for the parameter estimates. 
Figure 1: U.K. Yield-Curve Fit
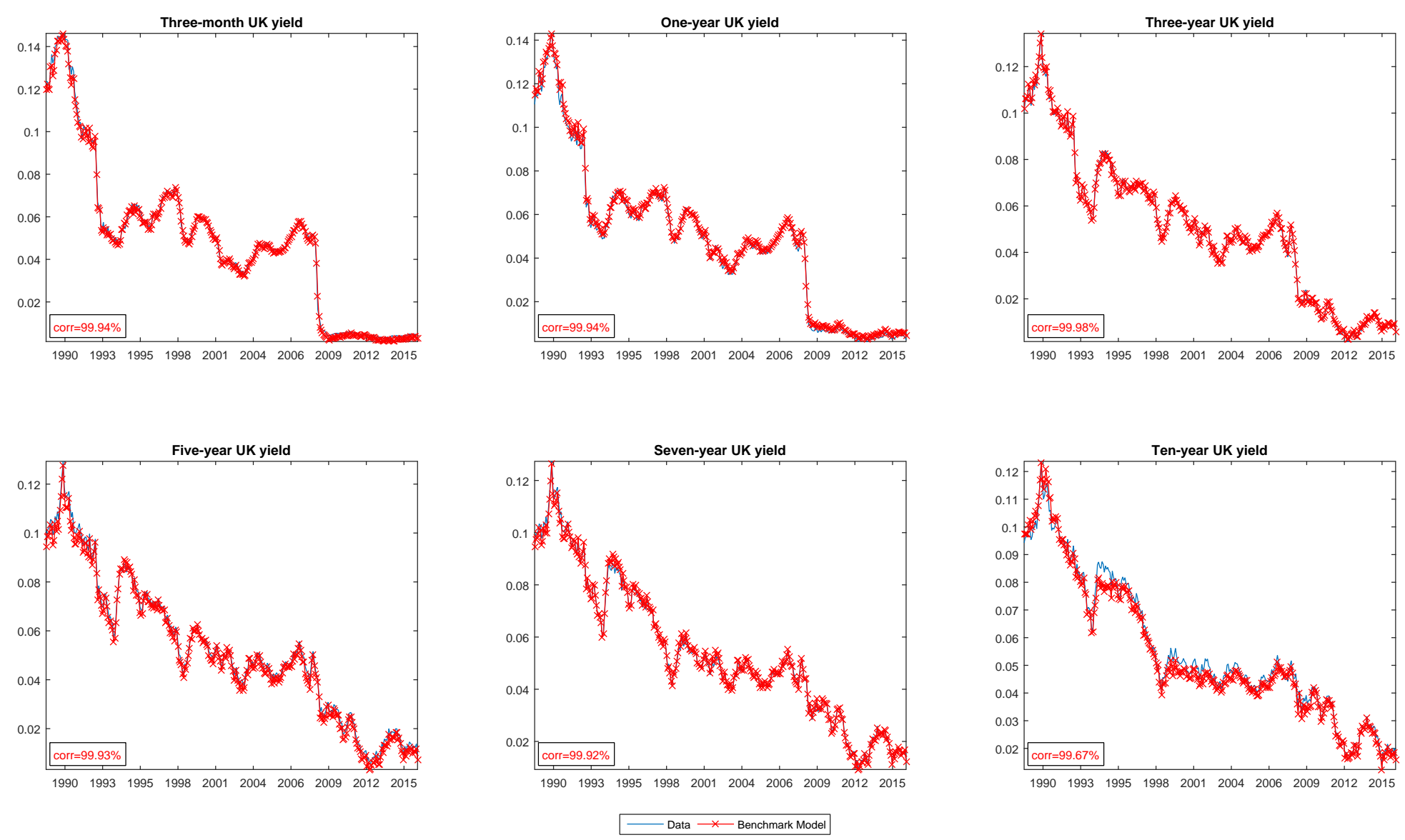
Figure 2: U.S. Yield-Curve Fit
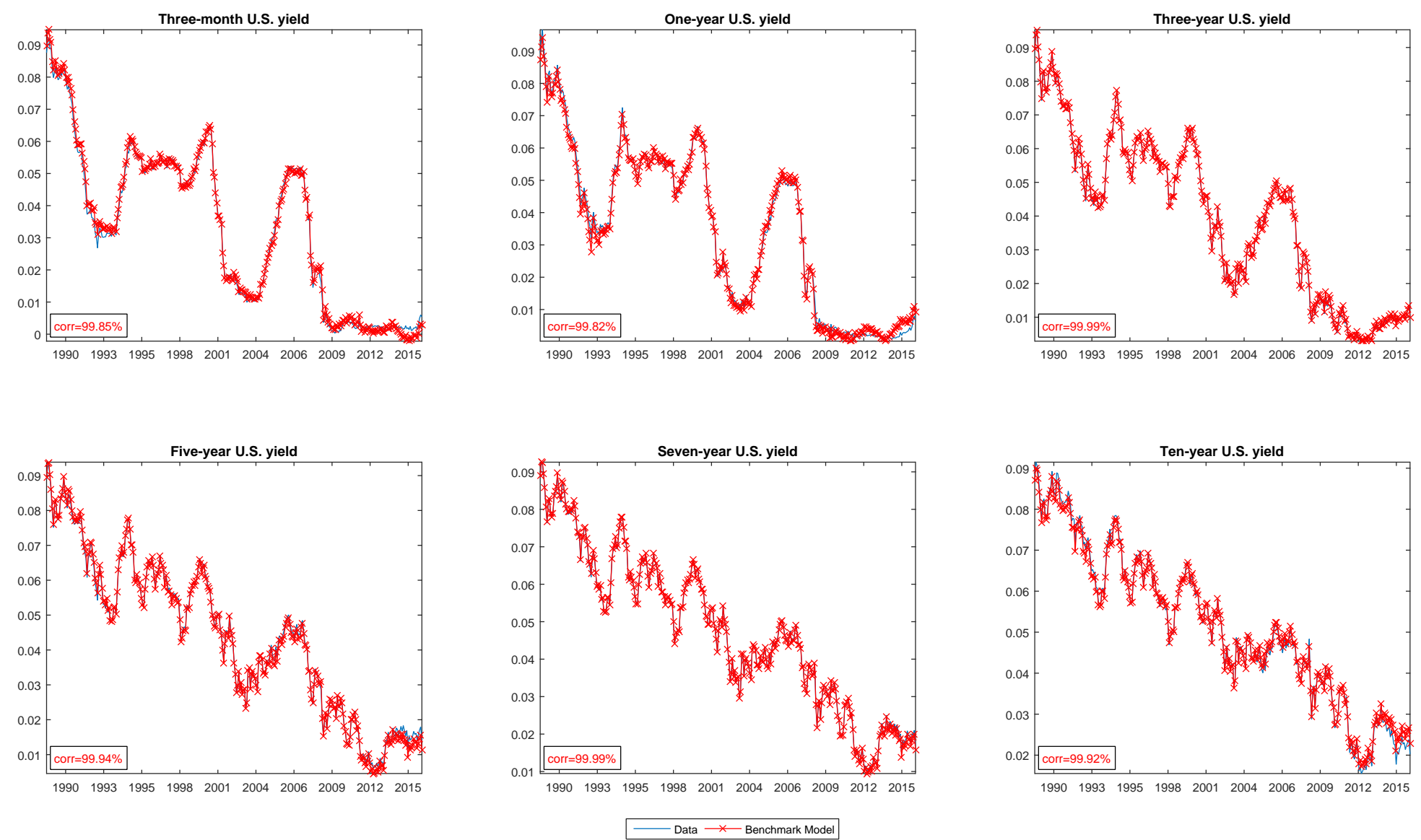
Figure 3: GBP/USD Exchange-Rate Fit
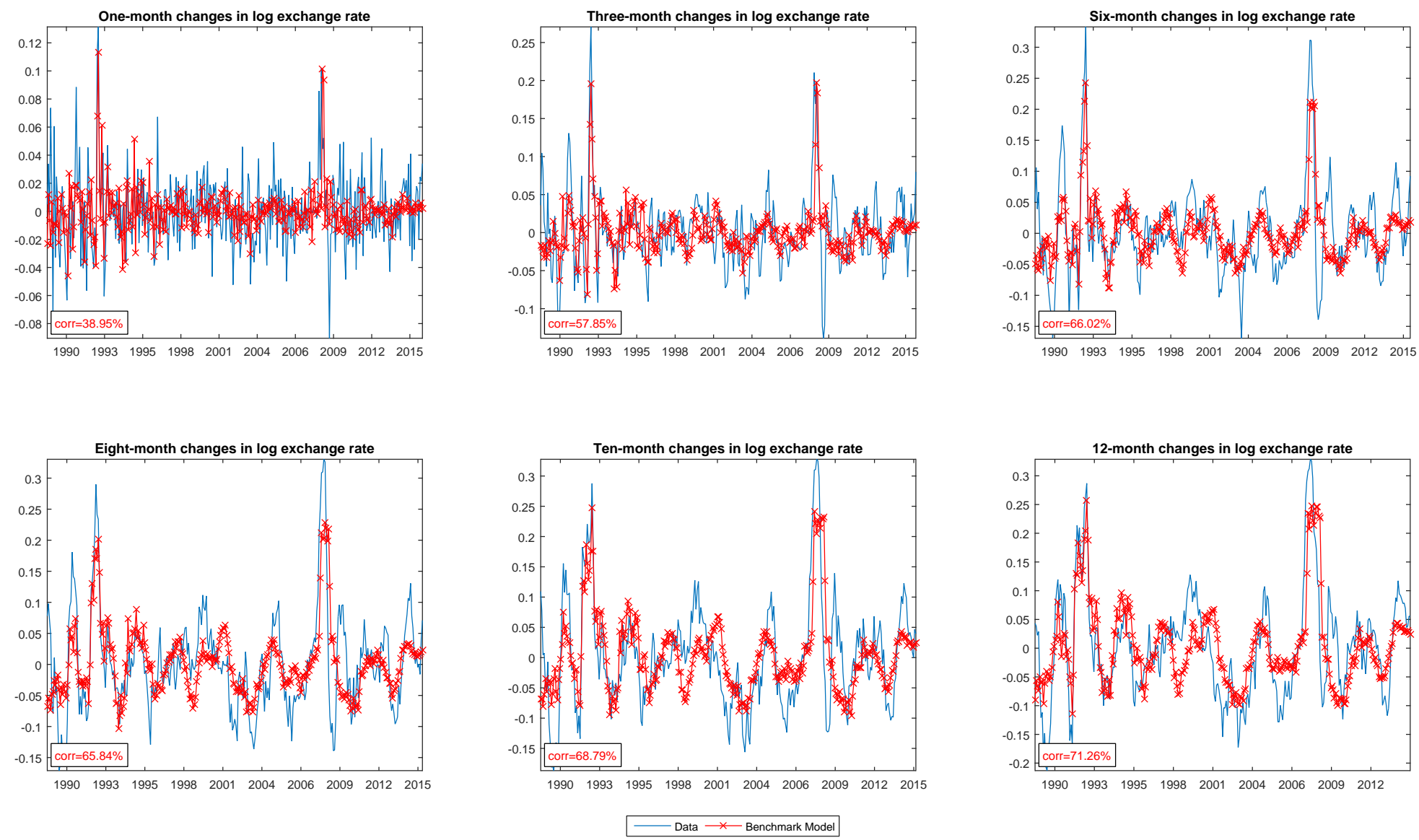
This type of behavior is observed not only in exchange rate movements, but in other assets as well, see Cochrane (2011). The equity returns literature, for example, finds the price-dividend ratio to be a long-run predictable component of stock returns, e.g., Fama and French (1988) and Cochrane (2008). The intuition suggests that although short-term movements are not well understood, at longer horizons factors and fundamentals are better able to capture the signal that drives movements in asset returns.

In order to obtain a general measure of goodness of fit, log currency returns are projected onto the model-implied exchange rate at horizon $k$ for each currency,

$$
\Delta s_{t, t+k}^{o b s}=\alpha_{k}+\beta_{k} \Delta s_{t, t+k}+\mu_{t+k} .
$$

Table 4 displays the results from regression (12), at horizon $k$, from one to twelve months. Given that the domestic country is the U.S., an increase in $\Delta s_{t}$ represents a depreciation of the U.S. dollar with respect to the currency of foreign country $*$. The projection of observed exchange rate movements onto the modelimplied currency returns yields $R^{2}$ that range between 0 and 15 percent at the one-month horizon, increase to 25-43 percent at the six-month horizon, and approach 50 percent at the one-year horizon.

One of the potential concerns when modeling exchange rates is small-sample bias. Small-sample bias arises due to the high persistence of the data and the short length of the sample. Closer to a unit root, there is larger small-sample bias in Maximum Likelihood estimates. The Joslin et al. (2011) estimation method enforces a high degree of persistence under the physical distribution of the factors to ensure a stationary process, i.e., constrains the eigenvalues that govern the speed of mean reversion to be strictly positive. To correct for small-sample bias and potential autocorrelation and heteroskedasticity in the regression error, Newey-West and Hansen-Hodrick standard errors are estimated. This generates larger standard errors that specify the precision of the estimated coefficients. In this case, the mean of the error is around zero and its standard deviation is small.

All coefficients are statistically significant at the 99 percent level (except for one/two-month CAD/USD), regardless of the method used to calculate standard errors. Moreover, the null hypothesis of no predictability in equation (12) is rejected for all currencies and the null hypothesis that $\alpha=0$ and $\beta=1$ cannot be rejected for horizons greater than two months. The table also shows simulation-based (5,000 bootstrap) 95 percent confidence intervals for the $R^{2}$. As the horizon increases the confidence intervals get tighter around the $R^{2}$ estimate. The takeaway of results in Table 4 is that about half of the variation in one-year exchange rate movements can be contemporaneously captured by interest rate factors, given the exchange rate specification from equation (11).

To further assess goodness of fit, model and data sample moments are compared across different horizons. 
The tests for equal sample moments in table 5 indicate that the model's mean and first-order autocorrelation are not statistically different from the data, and the largest deviations are given by the differences in variances, which is an area that warrants improvement. This is consistent with what Brandt and Santa-Clara (2002) call excess volatility of exchange rates, the fact that there seems to be substantial variation in exchange rates that is orthogonal to the cross-section of interest rates.

\subsection{Yield-Curve-Exchange-Rate Fit Trade-Off}

As pointed out in Sarno et al. (2012), an empirical trade-off emerges when simultaneously estimating yield curves and exchange rates. ${ }^{10}$ This is explored in detail by comparing the yield-curve fit under different models.

A model in which yield curves are independently estimated provides an upper bound on the goodness of fit the canonical term structure model can achieve -increasing the parameter space only lowers the goodness of fit. For the U.S., the RMSE are 1.8 to 6.3 basis points for the 1983-2016 period and 1.7 to 6.0 basis points for the 1990-2016 period. For the foreign countries, RMSE are between 2.2 and 14.2 basis points. The exceptions are the Australian six-month, one-year, and two-year yields (RMSE are 27.4, 22.2 and 15.5 basis points, respectively) and the Swiss one-year yield (RMSE are 20.6 basis points). A visual inspection of the yield curve data relative to the model suggests that the fit of the one-year Swiss yield is at its worse during the early 1990's and the post-2008 period, whereas Australia's one-year model-implied yield deviates from the data during the late 1980's, early 1990's.

On average, the mean of the error is around zero, with higher standard deviations for the countries that exhibit larger pricing errors. Nevertheless, the overall fit of the model as shown in figures 1 and 2 is very good, which suggests the model is flexible enough to account for very different yield curve shapes and dynamics. Moreover, we cannot reject the null hypothesis that the model is the same as the data, when comparing means, standard deviations, and first-order autocorrelations of the yields. The joint estimation of two countries' yield curves does not worsen the fit of either yield curve.

Comparing this independent yield curve model to the benchmark specification that jointly estimates the yield curves and the exchange rate indicates that for some countries, the yield RMSE are about the same as the independent yield curve models (e.g., Canada and Switzerland), but the fit for some others worsens (e.g., Norway and the U.K.). The worst fit is for the Australian yield curve, with RMSE between 17 and

\footnotetext{
${ }^{10}$ Sarno et al. (2012) derive two models: a global model in which everything is jointly estimated that is able to match depreciation rates, and individual yield curve models that match bond prices pretty well. They conclude that neither model can match both features simultaneously. Similarly to this paper, they explore the relationship between yields and currency returns through time-varying interest rate factors. A key difference relative to the framework in this paper is their linear specification of the stochastic discount factor, stemming from their chosen square root process of the variance as in Cox et al. (1985), which ensures the variance never goes negative such that the distribution is not normal but Chi square.
} 
Table 4: $\quad$ Model Fit for Exchange Rate Changes (in USD)

\begin{tabular}{|c|c|c|c|c|c|c|c|c|c|c|}
\hline Horizon: & & 1-month & 2-month & 3-month & 4-month & 5-month & 6-month & 8-month & 10 -month & 12-month \\
\hline Sample: & \multicolumn{10}{|c|}{ Jan-1983 to Jan-2016 } \\
\hline AUD & $\begin{array}{c}\beta \\
N . W . \\
H . H . \\
\chi_{\beta=0}^{2} \\
\chi_{\alpha=0, \beta=1}^{2} \\
R^{2} \\
{\left[R_{L}^{2}, R_{H}^{2}\right]} \\
\end{array}$ & $\begin{array}{c}0.415^{* * *} \\
(0.109) \\
(0.111) \\
1.4 \mathrm{e}+01\langle 0.00\rangle \\
28.3\langle 0.00\rangle \\
\mathbf{0 . 0 6} \\
{[0.02,0.11]} \\
\end{array}$ & $\begin{array}{c}0.537^{* * *} \\
(0.120) \\
(0.118) \\
2.1 \mathrm{e}+01\langle 0.00\rangle \\
15.8\langle 0.00\rangle \\
\mathbf{0 . 1 1} \\
{[0.06,0.18]} \\
\end{array}$ & $\begin{array}{c}0.703^{* * *} \\
(0.132) \\
(0.139) \\
2.5 \mathrm{e}+01\langle 0.00\rangle \\
4.6\langle 0.10\rangle \\
\mathbf{0 . 2 1} \\
{[0.14,0.28]} \\
\end{array}$ & $\begin{array}{c}0.830^{* * *} \\
(0.145) \\
(0.162) \\
2.6 \mathrm{e}+01\langle 0.00\rangle \\
1.1\langle 0.57\rangle \\
\mathbf{0 . 2 9} \\
{[0.21,0.37]} \\
\end{array}$ & $\begin{array}{c}0.879^{* * *} \\
(0.149) \\
(0.168) \\
2.7 \mathrm{e}+01\langle 0.00\rangle \\
0.5\langle 0.77\rangle \\
\mathbf{0 . 3 3} \\
{[0.25,0.42]} \\
\end{array}$ & $\begin{array}{c}0.908^{* * *} \\
(0.150) \\
(0.172) \\
2.8 \mathrm{e}+01\langle 0.00\rangle \\
0.3\langle 0.86\rangle \\
\mathbf{0 . 3 7} \\
{[0.29,0.45]} \\
\end{array}$ & $\begin{array}{c}0.956^{* * *} \\
(0.147) \\
(0.170) \\
3.1 \mathrm{e}+01\langle 0.00\rangle \\
0.1\langle 0.96\rangle \\
\mathbf{0 . 4 1} \\
{[0.34,0.48]} \\
\end{array}$ & $\begin{array}{c}0.957^{* * *} \\
(0.130) \\
(0.150) \\
4.1 \mathrm{e}+01\langle 0.00\rangle \\
0.1\langle 0.94\rangle \\
\mathbf{0 . 4 4} \\
{[0.37,0.50]} \\
\end{array}$ & $\begin{array}{c}0.925^{* * *} \\
(0.119) \\
(0.138) \\
4.5 \mathrm{e}+01\langle 0.00\rangle \\
0.5\langle 0.79\rangle \\
\mathbf{0 . 4 3} \\
{[0.37,0.49]} \\
\end{array}$ \\
\hline Sample: & \multicolumn{10}{|c|}{ Jan-1990 to Jan-2016 } \\
\hline $\mathrm{CAD}$ & $\begin{array}{c}\beta \\
N . W . \\
H . H . \\
\chi_{\beta=0}^{2} \\
\chi_{\alpha=0, \beta=1}^{2} \\
R^{2} \\
{\left[R_{L}^{2}, R_{H}^{2}\right]} \\
\end{array}$ & $\begin{array}{c}0.094 \\
(0.142) \\
(0.154) \\
3.7 \mathrm{e}-01\langle 0.54\rangle \\
35.0\langle 0.00\rangle \\
\mathbf{0 . 0 0} \\
{[-0.00,0.03]}\end{array}$ & $\begin{array}{c}0.403^{* *} \\
(0.159) \\
(0.167) \\
5.8 \mathrm{e}+00\langle 0.02\rangle \\
12.9\langle 0.00\rangle \\
\mathbf{0 . 0 6} \\
{[0.01,0.15]} \\
\end{array}$ & $\begin{array}{c}0.493^{* * *} \\
(0.168) \\
(0.179) \\
7.6 \mathrm{e}+00\langle 0.01\rangle \\
8.0\langle 0.02\rangle \\
\mathbf{0 . 0 9} \\
{[0.03,0.18]} \\
\end{array}$ & $\begin{array}{c}0.615^{* * *} \\
(0.177) \\
(0.197) \\
9.8 \mathrm{e}+00\langle 0.00\rangle \\
3.9\langle 0.15\rangle \\
\mathbf{0 . 1 5} \\
{[0.07,0.25]}\end{array}$ & $\begin{array}{c}0.715^{* * *} \\
(0.181) \\
(0.209) \\
1.2 \mathrm{e}+01\langle 0.00\rangle \\
2.0\langle 0.37\rangle \\
\mathbf{0 . 1 9} \\
{[0.11,0.28]} \\
\end{array}$ & $\begin{array}{c}0.827^{* * *} \\
(0.187) \\
(0.222) \\
1.4 \mathrm{e}+01\langle 0.00\rangle \\
0.8\langle 0.68\rangle \\
\mathbf{0 . 2 5} \\
{[0.16,0.34]} \\
\end{array}$ & $\begin{array}{c}0.941 * * * \\
(0.175) \\
(0.208) \\
2.1 \mathrm{e}+01\langle 0.00\rangle \\
0.3\langle 0.87\rangle \\
\mathbf{0 . 3 1} \\
{[0.23,0.39]} \\
\end{array}$ & $\begin{array}{c}1.067^{* * *} \\
(0.176) \\
(0.208) \\
2.6 \mathrm{e}+01\langle 0.00\rangle \\
0.2\langle 0.89\rangle \\
\mathbf{0 . 3 9} \\
{[0.31,0.46]} \\
\end{array}$ & $\begin{array}{c}1.173^{* * *} \\
(0.182) \\
(0.226) \\
2.7 \mathrm{e}+01\langle 0.00\rangle \\
0.6\langle 0.74\rangle \\
\mathbf{0 . 4 5} \\
{[0.38,0.53]} \\
\end{array}$ \\
\hline Sample: & \multicolumn{10}{|c|}{ Jan-1985 to Jan-2016 } \\
\hline JPY & $\begin{array}{c}\beta \\
N . W . \\
H . H . \\
\chi_{\beta=0}^{2} \\
\chi_{\alpha=0, \beta=1}^{2} \\
R^{2} \\
{\left[R_{L}^{2}, R_{H}^{2}\right]} \\
\end{array}$ & $\begin{array}{c}0.386^{* * * *} \\
(0.099) \\
(0.106) \\
1.3 \mathrm{e}+01\langle 0.00\rangle \\
33.4\langle 0.00\rangle \\
\mathbf{0 . 0 5} \\
{[0.02,0.10]} \\
\end{array}$ & $\begin{array}{c}0.562^{* * *} \\
(0.095) \\
(0.101) \\
3.1 \mathrm{e}+01\langle 0.00\rangle \\
19.4\langle 0.00\rangle \\
\mathbf{0 . 1 2} \\
{[0.06,0.18]} \\
\end{array}$ & $\begin{array}{c}0.747^{* * *} \\
(0.103) \\
(0.111) \\
4.5 \mathrm{e}+01\langle 0.00\rangle \\
5.6\langle 0.06\rangle \\
\mathbf{0 . 2 0} \\
{[0.14,0.28]} \\
\end{array}$ & $\begin{array}{c}0.840^{* * * *} \\
(0.104) \\
(0.112) \\
5.6 \mathrm{e}+01\langle 0.00\rangle \\
2.4\langle 0.30\rangle \\
\mathbf{0 . 2 7} \\
{[0.20,0.34]} \\
\end{array}$ & $\begin{array}{c}0.901 * * * \\
(0.104) \\
(0.113) \\
6.3 \mathrm{e}+01\langle 0.00\rangle \\
1.0\langle 0.61\rangle \\
\mathbf{0 . 3 1} \\
{[0.25,0.38]} \\
\end{array}$ & $\begin{array}{c}0.964^{* * *} \\
(0.109) \\
(0.119) \\
6.5 \mathrm{e}+01\langle 0.00\rangle \\
0.2\langle 0.91\rangle \\
\mathbf{0 . 3 7} \\
{[0.31,0.44]} \\
\end{array}$ & $\begin{array}{c}0.994^{* * *} \\
(0.118) \\
(0.130) \\
5.8 \mathrm{e}+01\langle 0.00\rangle \\
0.1\langle 0.97\rangle \\
\mathbf{0 . 4 5} \\
{[0.39,0.52]} \\
\end{array}$ & $\begin{array}{c}1.005^{* * *} \\
(0.123) \\
(0.135) \\
5.6 \mathrm{e}+01\langle 0.00\rangle \\
0.1\langle 0.97\rangle \\
\mathbf{0 . 4 9} \\
{[0.42,0.56]} \\
\end{array}$ & $\begin{array}{c}1.032^{* * *} \\
(0.117) \\
(0.130) \\
6.3 \mathrm{e}+01\langle 0.00\rangle \\
0.1\langle 0.94\rangle \\
\mathbf{0 . 5 3} \\
{[0.46,0.59]} \\
\end{array}$ \\
\hline Sample: & \multicolumn{10}{|c|}{ Jan-1990 to Jan-2016 } \\
\hline NOK & $\begin{array}{c}\beta \\
N . W . \\
H . H . \\
\chi_{\beta=0}^{2} \\
\chi_{\alpha=0, \beta=1}^{2} \\
R^{2} \\
{\left[R_{L}^{2}, R_{H}^{2}\right]} \\
\end{array}$ & $\begin{array}{c}0.506^{* * *} \\
(0.111) \\
(0.119) \\
1.8 \mathrm{e}+01\langle 0.00\rangle \\
18.3\langle 0.00\rangle \\
\mathbf{0 . 0 9} \\
{[0.04,0.16]} \\
\end{array}$ & $\begin{array}{c}0.689^{* * *} \\
(0.104) \\
(0.110) \\
4.0 \mathrm{e}+01\langle 0.00\rangle \\
9.5\langle 0.01\rangle \\
\mathbf{0 . 2 0} \\
{[0.12,0.28]} \\
\end{array}$ & $\begin{array}{c}0.777^{* * *} \\
(0.119) \\
(0.126) \\
3.8 \mathrm{e}+01\langle 0.00\rangle \\
4.4\langle 0.11\rangle \\
\mathbf{0 . 2 6} \\
{[0.18,0.35]} \\
\end{array}$ & $\begin{array}{c}0.859^{* * *} \\
(0.133) \\
(0.143) \\
3.6 \mathrm{e}+01\langle 0.00\rangle \\
1.6\langle 0.44\rangle \\
\mathbf{0 . 3 2} \\
{[0.23,0.39]} \\
\end{array}$ & $\begin{array}{c}0.896^{* * *} \\
(0.140) \\
(0.156) \\
3.3 \mathrm{e}+01\langle 0.00\rangle \\
0.9\langle 0.64\rangle \\
\mathbf{0 . 3 5} \\
{[0.27,0.43]} \\
\end{array}$ & $\begin{array}{c}0.922^{* * *} \\
(0.145) \\
(0.160) \\
3.3 \mathrm{e}+01\langle 0.00\rangle \\
0.6\langle 0.74\rangle \\
\mathbf{0 . 3 7} \\
{[0.28,0.45]} \\
\end{array}$ & $\begin{array}{c}0.904^{* * *} \\
(0.148) \\
(0.168) \\
2.9 \mathrm{e}+01\langle 0.00\rangle \\
0.7\langle 0.72\rangle \\
\mathbf{0 . 3 6} \\
{[0.29,0.44]} \\
\end{array}$ & $\begin{array}{c}0.917^{* * *} \\
(0.147) \\
(0.166) \\
3.0 \mathrm{e}+01\langle 0.00\rangle \\
0.6\langle 0.76\rangle \\
\mathbf{0 . 4 0} \\
{[0.32,0.47]} \\
\end{array}$ & $\begin{array}{c}0.927^{* * *} \\
(0.149) \\
(0.165) \\
3.1 \mathrm{e}+01\langle 0.00\rangle \\
0.5\langle 0.77\rangle \\
\mathbf{0 . 4 2} \\
{[0.34,0.49]} \\
\end{array}$ \\
\hline Sample: & \multicolumn{10}{|c|}{ Feb-1984 to Dec-2015 } \\
\hline SEK & $\begin{array}{c}\beta \\
N . W . \\
H . H . \\
\chi_{\beta=0}^{2} \\
\chi_{\alpha=0, \beta=1}^{2} \\
R^{2} \\
{\left[R_{L}^{2}, R_{H}^{2}\right]}\end{array}$ & $\begin{array}{c}0.309^{* * *} \\
(0.070) \\
(0.059) \\
2.7 \mathrm{e}+01\langle 0.00\rangle \\
143.3\langle 0.00\rangle \\
\mathbf{0 . 0 7} \\
{[0.02,0.14]} \\
\end{array}$ & $\begin{array}{c}0.480^{* * *} \\
(0.109) \\
(0.109) \\
1.9 \mathrm{e}+01\langle 0.00\rangle \\
23.5\langle 0.00\rangle \\
\mathbf{0 . 1 5} \\
{[0.06,0.27]}\end{array}$ & $\begin{array}{c}0.590^{* * *} \\
(0.123) \\
(0.127) \\
2.1 \mathrm{e}+01\langle 0.00\rangle \\
10.4\langle 0.01\rangle \\
\mathbf{0 . 2 0} \\
{[0.10,0.31]} \\
\end{array}$ & $\begin{array}{c}0.719^{* * *} \\
(0.148) \\
(0.162) \\
2.0 \mathrm{e}+01\langle 0.00\rangle \\
4.0\langle 0.13\rangle \\
\mathbf{0 . 2 5} \\
{[0.15,0.35]}\end{array}$ & $\begin{array}{c}0.848^{* * *} \\
(0.156) \\
(0.171) \\
2.5 \mathrm{e}+01\langle 0.00\rangle \\
2.8\langle 0.25\rangle \\
\mathbf{0 . 3 0} \\
{[0.21,0.40]} \\
\end{array}$ & $\begin{array}{c}0.948^{* * *} \\
(0.151) \\
(0.165) \\
3.3 \mathrm{e}+01\langle 0.00\rangle \\
2.9\langle 0.24\rangle \\
\mathbf{0 . 3 5} \\
{[0.26,0.44]}\end{array}$ & $\begin{array}{c}1.046^{* * *} \\
(0.147) \\
(0.165) \\
4.0 \mathrm{e}+01\langle 0.00\rangle \\
3.0\langle 0.22\rangle \\
\mathbf{0 . 3 9} \\
{[0.31,0.46]} \\
\end{array}$ & $\begin{array}{c}1.133^{* * * *} \\
(0.144) \\
(0.155) \\
5.4 \mathrm{e}+01\langle 0.00\rangle \\
3.3\langle 0.19\rangle \\
\mathbf{0 . 4 3} \\
{[0.35,0.51]} \\
\end{array}$ & $\begin{array}{c}1.180^{* * *} \\
(0.147) \\
(0.148) \\
6.3 \mathrm{e}+01\langle 0.00\rangle \\
3.5\langle 0.17\rangle \\
\mathbf{0 . 4 5} \\
{[0.37,0.52]} \\
\end{array}$ \\
\hline Sample: & \multicolumn{10}{|c|}{ Jan-1988 to Dec-2015 } \\
\hline $\mathrm{CHF}$ & $\begin{array}{c}\beta \\
N . W . \\
H . H . \\
\chi_{\beta=0}^{2} \\
\chi_{\alpha=0, \beta=1}^{2} \\
R^{2} \\
{\left[R_{L}^{2}, R_{H}^{2}\right]} \\
\end{array}$ & $\begin{array}{c}0.377^{* * * *} \\
(0.105) \\
(0.118) \\
1.0 \mathrm{e}+01\langle 0.00\rangle \\
28.1\langle 0.00\rangle \\
\mathbf{0 . 0 6} \\
{[0.02,0.11]} \\
\end{array}$ & $\begin{array}{c}0.539^{* * *} \\
(0.110) \\
(0.122) \\
2.0 \mathrm{e}+01\langle 0.00\rangle \\
14.5\langle 0.00\rangle \\
\mathbf{0 . 1 2} \\
{[0.07,0.18]} \\
\end{array}$ & $\begin{array}{c}0.685^{* * *} \\
(0.108) \\
(0.125) \\
3.0 \mathrm{e}+01\langle 0.00\rangle \\
6.4\langle 0.04\rangle \\
\mathbf{0 . 2 0} \\
{[0.14,0.27]} \\
\end{array}$ & $\begin{array}{c}0.817^{* * *} \\
(0.111) \\
(0.125) \\
4.3 \mathrm{e}+01\langle 0.00\rangle \\
2.1\langle 0.34\rangle \\
\mathbf{0 . 2 7} \\
{[0.20,0.35]} \\
\end{array}$ & $\begin{array}{c}0.877^{* * *} \\
(0.108) \\
(0.119) \\
5.4 \mathrm{e}+01\langle 0.00\rangle \\
1.1\langle 0.57\rangle \\
\mathbf{0 . 3 2} \\
{[0.24,0.39]} \\
\end{array}$ & $\begin{array}{c}0.937^{* * *} \\
(0.106) \\
(0.116) \\
6.5 \mathrm{e}+01\langle 0.00\rangle \\
0.5\langle 0.80\rangle \\
\mathbf{0 . 3 7} \\
{[0.29,0.44]} \\
\end{array}$ & $\begin{array}{c}0.963^{* * *} \\
(0.114) \\
(0.122) \\
6.3 \mathrm{e}+01\langle 0.00\rangle \\
0.4\langle 0.81\rangle \\
\mathbf{0 . 4 1} \\
{[0.33,0.48]} \\
\end{array}$ & $\begin{array}{c}1.003^{* * *} \\
(0.114) \\
(0.114) \\
7.7 \mathrm{e}+01\langle 0.00\rangle \\
0.4\langle 0.82\rangle \\
\mathbf{0 . 4 4} \\
{[0.37,0.51]} \\
\end{array}$ & $\begin{array}{c}1.048^{* * *} \\
(0.100) \\
(0.096) \\
1.2 \mathrm{e}+02\langle 0.00\rangle \\
0.7\langle 0.72\rangle \\
\mathbf{0 . 4 9} \\
{[0.43,0.56]} \\
\end{array}$ \\
\hline Sample: & \multicolumn{10}{|c|}{ Jan-1989 to Jan-2016 } \\
\hline GBP & $\begin{array}{c}\beta \\
N . W . \\
H . H . \\
\chi_{\beta=0}^{2} \\
\chi_{\alpha=0, \beta=1}^{2} \\
R^{2} \\
{\left[R_{L}^{2}, R_{H}^{2}\right]}\end{array}$ & $\begin{array}{c}0.651^{* * *} \\
(0.138) \\
(0.147) \\
2.0 \mathrm{e}+01\langle 0.00\rangle \\
6.8\langle 0.03\rangle \\
\mathbf{0 . 1 5} \\
{[0.06,0.26]}\end{array}$ & $\begin{array}{c}0.850^{* * *} \\
(0.137) \\
(0.136) \\
3.9 \mathrm{e}+01\langle 0.00\rangle \\
1.4\langle 0.49\rangle \\
\mathbf{0 . 2 8} \\
{[0.14,0.41]}\end{array}$ & $\begin{array}{c}0.921^{* * *} \\
(0.132) \\
(0.142) \\
4.2 \mathrm{e}+01\langle 0.00\rangle \\
0.4\langle 0.82\rangle \\
\mathbf{0 . 3 3} \\
{[0.19,0.46]}\end{array}$ & $\begin{array}{c}0.985^{* * *} \\
(0.128) \\
(0.139) \\
5.0 \mathrm{e}+01\langle 0.00\rangle \\
0.0\langle 0.98\rangle \\
\mathbf{0 . 3 8} \\
{[0.25,0.50]}\end{array}$ & $\begin{array}{c}1.022^{* * *} \\
(0.134) \\
(0.142) \\
5.2 \mathrm{e}+01\langle 0.00\rangle \\
0.0\langle 0.98\rangle \\
\mathbf{0 . 4 2} \\
{[0.29,0.53]}\end{array}$ & $\begin{array}{c}1.019^{* * *} \\
(0.142) \\
(0.139) \\
5.4 \mathrm{e}+01\langle 0.00\rangle \\
0.0\langle 0.99\rangle \\
\mathbf{0 . 4 3} \\
{[0.30,0.54]}\end{array}$ & $\begin{array}{c}0.968^{* * *} \\
(0.149) \\
(0.129) \\
5.6 \mathrm{e}+01\langle 0.00\rangle \\
0.1\langle 0.97\rangle \\
\mathbf{0 . 4 3} \\
{[0.32,0.54]}\end{array}$ & $\begin{array}{c}0.939^{* * *} \\
(0.135) \\
(0.123) \\
5.8 \mathrm{e}+01\langle 0.00\rangle \\
0.3\langle 0.86\rangle \\
\mathbf{0 . 4 7} \\
{[0.37,0.56]}\end{array}$ & $\begin{array}{c}0.923^{* * *} \\
(0.124) \\
(0.122) \\
5.8 \mathrm{e}+01\langle 0.00\rangle \\
0.6\langle 0.74\rangle \\
\mathbf{0 . 5 1} \\
{[0.42,0.59]} \\
\end{array}$ \\
\hline
\end{tabular}

Notes: Estimates for $\Delta s_{t, t+k}^{o b s}=\alpha_{k}+\beta_{k} \Delta s_{t, t+k}+\mu_{t+k}$, where $\Delta s_{t, t+k}^{o b s}$ is the observed log exchange rate change in USD between $t$ and $t+k$ and $\Delta s_{t, t+k}$ is the model-implied log exchange rate change, modeled as the ratio of two countries' log pricing kernels where the domestic country is the U.S. N.W. refers to

Newey-West standard errors and H.H. refers to Hansen-Hodrick standard errors, where the lag is equal to the horizon $k+1$ (in months). The significance level of the coefficient is determined by $N . W$. and is indicated by $\left(^{*}\right)$ where ${ }^{* * *} \mathrm{p}<0.01,{ }^{* *} \mathrm{p}<0.05,{ }^{*} \mathrm{p}<0.1 . \quad \chi_{\beta=0}^{2}$ tests the null hypothesis $\beta=0$ and $\chi_{\alpha=0, \beta=1}^{2}$ tests the null hypothesis $\alpha=0$ and $\beta=1$. Both tests are performed with $H . H$. standard errors and p-values are reported in \langle\rangle$. R^{2}$ is adjusted for degrees of freedom and $\left[R_{L}^{2}, R_{H}^{2}\right]$ indicates the simulation-based (5,000 bootstrap) $95 \%$ confidence interval for the $R^{2}$. 
Table 5: $\quad$ Exchange Rates Sample Moments

\begin{tabular}{|c|c|c|c|c|c|c|c|c|c|c|}
\hline & & \multicolumn{3}{|c|}{ Mean } & \multicolumn{3}{|c|}{ Standard Deviation } & \multicolumn{3}{|c|}{ First Order Autocorrelation } \\
\hline & & 1-month & 6-month & 1-year & 1-month & 6-month & 1-year & 1-month & 6-month & 1-year \\
\hline \multirow[t]{3}{*}{ AUD } & Model & -0.001 & -0.004 & -0.008 & 0.020 & 0.060 & 0.089 & 0.172 & 0.867 & 0.944 \\
\hline & Data & -0.001 & -0.004 & -0.006 & 0.034 & 0.089 & 0.125 & 0.033 & 0.840 & 0.907 \\
\hline & pval: model=data & 0.988 & 0.933 & 0.826 & 0.000 & 0.000 & 0.000 & 0.038 & 0.389 & 0.120 \\
\hline \multirow[t]{3}{*}{ CAD } & Model & -0.001 & -0.004 & -0.008 & 0.015 & 0.034 & 0.046 & -0.136 & 0.790 & 0.905 \\
\hline & Data & -0.001 & -0.003 & -0.004 & 0.023 & 0.057 & 0.080 & -0.084 & 0.813 & 0.922 \\
\hline & pval: model=data & 0.908 & 0.625 & 0.461 & 0.000 & 0.000 & 0.000 & 0.510 & 0.614 & 0.586 \\
\hline \multirow[t]{3}{*}{ JPY } & Model & 0.002 & 0.013 & 0.026 & 0.019 & 0.056 & 0.089 & 0.060 & 0.883 & 0.946 \\
\hline & Data & 0.002 & 0.012 & 0.022 & 0.032 & 0.088 & 0.127 & 0.018 & 0.830 & 0.923 \\
\hline & pval: model=data & 0.871 & 0.800 & 0.599 & 0.000 & 0.000 & 0.000 & 0.538 & 0.096 & 0.292 \\
\hline \multirow[t]{3}{*}{ NOK } & Model & -0.000 & -0.001 & -0.000 & 0.020 & 0.056 & 0.081 & 0.121 & 0.843 & 0.923 \\
\hline & Data & -0.001 & -0.005 & -0.011 & 0.032 & 0.085 & 0.117 & 0.054 & 0.868 & 0.920 \\
\hline & pval: model=data & 0.792 & 0.438 & 0.189 & 0.000 & 0.000 & 0.000 & 0.365 & 0.448 & 0.906 \\
\hline \multirow[t]{3}{*}{ SEK } & Model & -0.002 & -0.015 & -0.029 & 0.029 & 0.057 & 0.073 & -0.104 & 0.722 & 0.840 \\
\hline & Data & -0.000 & -0.001 & -0.000 & 0.033 & 0.091 & 0.129 & 0.047 & 0.830 & 0.912 \\
\hline & pval: model=data & 0.340 & 0.013 & 0.000 & 0.018 & 0.000 & 0.000 & 0.023 & 0.004 & 0.012 \\
\hline \multirow[t]{3}{*}{ CHF } & Model & 0.001 & 0.004 & 0.009 & 0.021 & 0.051 & 0.071 & -0.025 & 0.800 & 0.890 \\
\hline & Data & 0.001 & 0.006 & 0.015 & 0.032 & 0.078 & 0.106 & -0.004 & 0.803 & 0.885 \\
\hline & pval: model=data & 0.872 & 0.657 & 0.400 & 0.000 & 0.000 & 0.000 & 0.776 & 0.946 & 0.884 \\
\hline \multirow[t]{3}{*}{ GBP } & Model & -0.000 & -0.002 & -0.004 & 0.016 & 0.047 & 0.072 & 0.096 & 0.869 & 0.933 \\
\hline & Data & -0.001 & -0.002 & -0.003 & 0.027 & 0.072 & 0.093 & 0.004 & 0.819 & 0.890 \\
\hline & pval: model $=$ data & 0.815 & 0.943 & 0.866 & 0.000 & 0.000 & 0.000 & 0.174 & 0.104 & 0.066 \\
\hline
\end{tabular}

Notes: "p-val: model=data" is the p-value of (1) a two-sample $t$-test for the null hypothesis that the data and the model-implied log exchange rate changes come from independent random samples from normal distributions with equal mean but unknown variances; (2) a two-sample $F$-test for the null hypothesis that the data and the model-implied log exchange rate changes come from normal distributions with the same variance; and (3) a $\chi^{2}$-test for the null hypothesis that the first-order autocorrelation coefficients from the data and the model-implied log exchange rate changes (estimated jointly using Seemingly Unrelated Regression) are the same, based on an asymptotic normal distribution for the parameter estimates.

44 basis points, compared to 2-22 basis points if modeled independently, whereas Canada's RMSE remain between 3.2 to 7 basis points after incorporating the exchange rate. Australia's worst fit under the joint model is during the 1980's, and for some maturities (e.g., 1 and 10 years) also the post-2014 period.

Nevertheless, even in the worst cases, the RMSE for the yields are still below half a percentage point, and as evidenced in the figures and tables in the Appendix, the model captures the yield-curve dynamics of all these countries relatively well, for some better than others. In general, the model-implied yields are indistinguishable from the data, even while jointly estimating the exchange rate, although some precision is expected to be lost as more degrees of freedom are introduced.

\section{Robustness and Further Analysis}

Bauer et al. (2012, 2014) find that estimating the Joslin et al. (2011) model by Maximum Likelihood can still lead to biased estimates. They propose to replace the initial parameters of the factors under $\mathbb{P}$ with simulation-based, bias-corrected estimates before the Maximum Likelihood estimation. I implement their suggested inverse bootstrap bias-corrected method: For each of the 5,000 bootstrap iterations (after discard- 
ing the first 1,000), a set of 50 bootstrap samples is simulated using trial parameters to calculate the mean or median of the OLS estimator to be equal to the original OLS estimate. The bias-corrected estimates then reflect more persistent factor dynamics, as measured by the largest eigenvalues of the transition matrix. This corrects for small-sample bias in the Maximum Likelihood estimates of the model.

Figures 4 (a) and 4 (b) show the $R^{2}$ at different horizons for the baseline model in red along with the 90 percent confidence intervals. As established in the previous section, the fit of the model improves as the horizon increases for every currency. The figures also indicate the bias-corrected counterpart $R^{2}$ at different horizons, showing very similar patterns across countries. After correcting for bias, interest rate factors are still able to explain as much variation in exchange rates. The same patterns as the baseline model can be observed, and as the horizon increases, the fit of the model improves for all currencies. Most importantly, results are robust to correcting for small-sample bias with different simulation-based bootstrapping methods. ${ }^{11}$

Finally, the figures show the $R^{2}$ when only non-overlapping observations are considered, which very closely follow the baseline model $R^{2}$, suggesting that small-sample bias from using overlapping periods is not likely an explanation behind the fit improvement at longer horizons. Results for the model with mean and median bias-corrected estimates along with the non-overlapping regression results can be found in the Appendix.

Besides accounting for small-sample bias, the model is re-estimated using a different domestic country. Letting the U.K. be the domestic country, for example, implies that exchange rates for foreign country $*$ are in terms of the British pound and no U.S.-specific information factors into the model. Estimating the USD/GBP exchange rate is the same as modeling the GBP/USD exchange rate, since results are symmetric. This is because it does not matter what country is selected as the domestic country; the information content in the factors remains the same. For all other countries, however, results will vary, usually fitting the exchange rate slightly better than the baseline model. The results of this exercise suggest that the U.S. is not driving the results and any two countries' yield curves are able to account for their currency fluctuations. Moreover, extending the horizon further up to five years, the fit of the model continues to significantly improve for all currencies.

In summary, interest rate factors alone account for about half of the one-year movements in the $\log$ exchange rate, and even more at even longer horizons. These results are robust to accounting for smallsample bias, the persistence in the autoregressive processes, different currencies and periods, changing the country base, and only considering non-overlapping observations.

\footnotetext{
${ }^{11}$ The VAR physical dynamics are more persistent after correcting for bias, although estimates for $\Sigma$ remain close to the estimates of the unrestricted VAR.
} 
Figure 4 (a): Exchange-Rate Fit Robustness
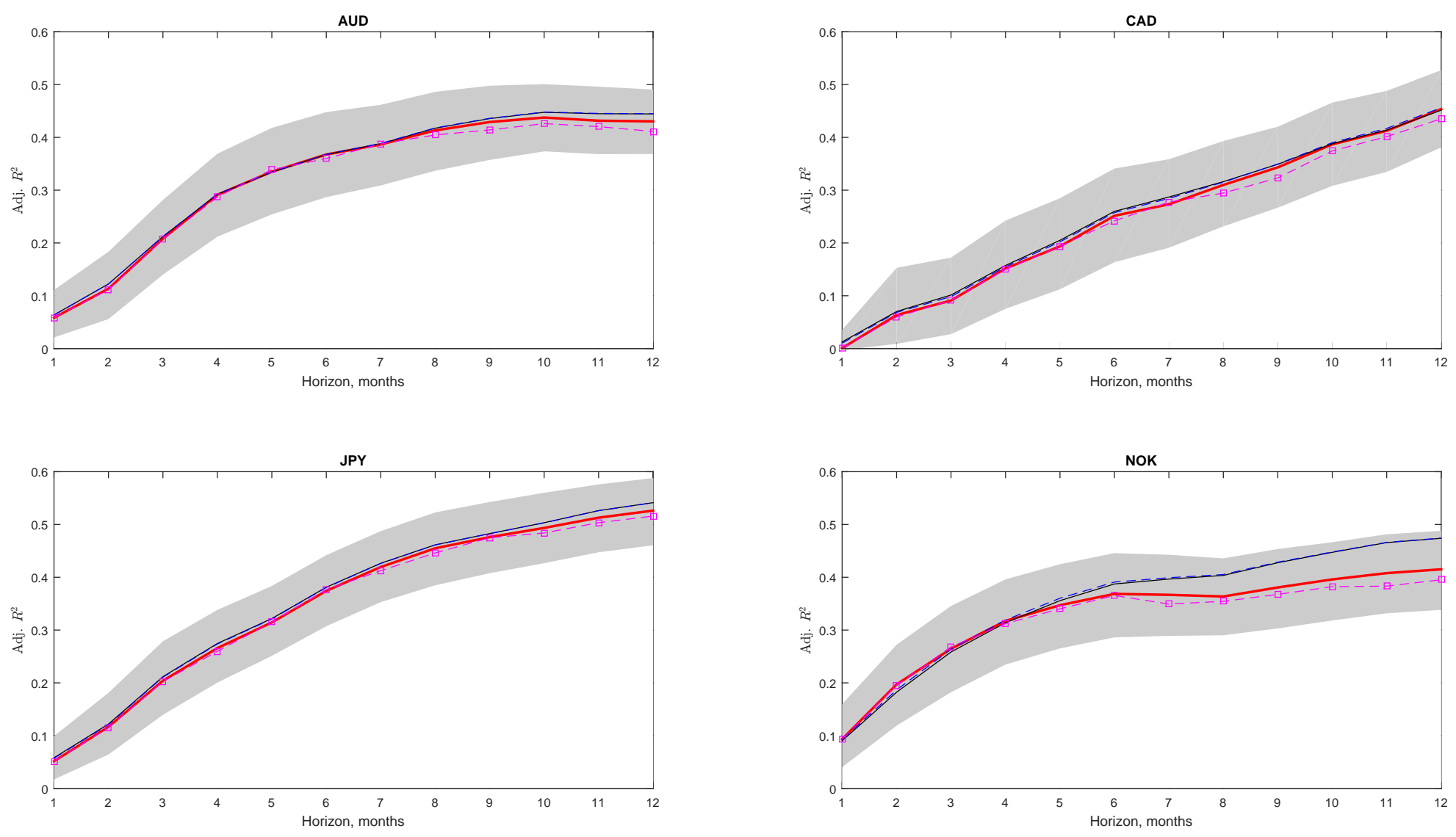

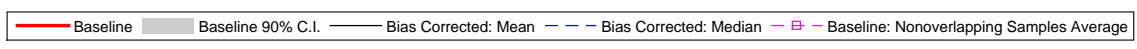


Figure $4(\mathrm{~b})$ : Exchange-Rate Fit Robustness
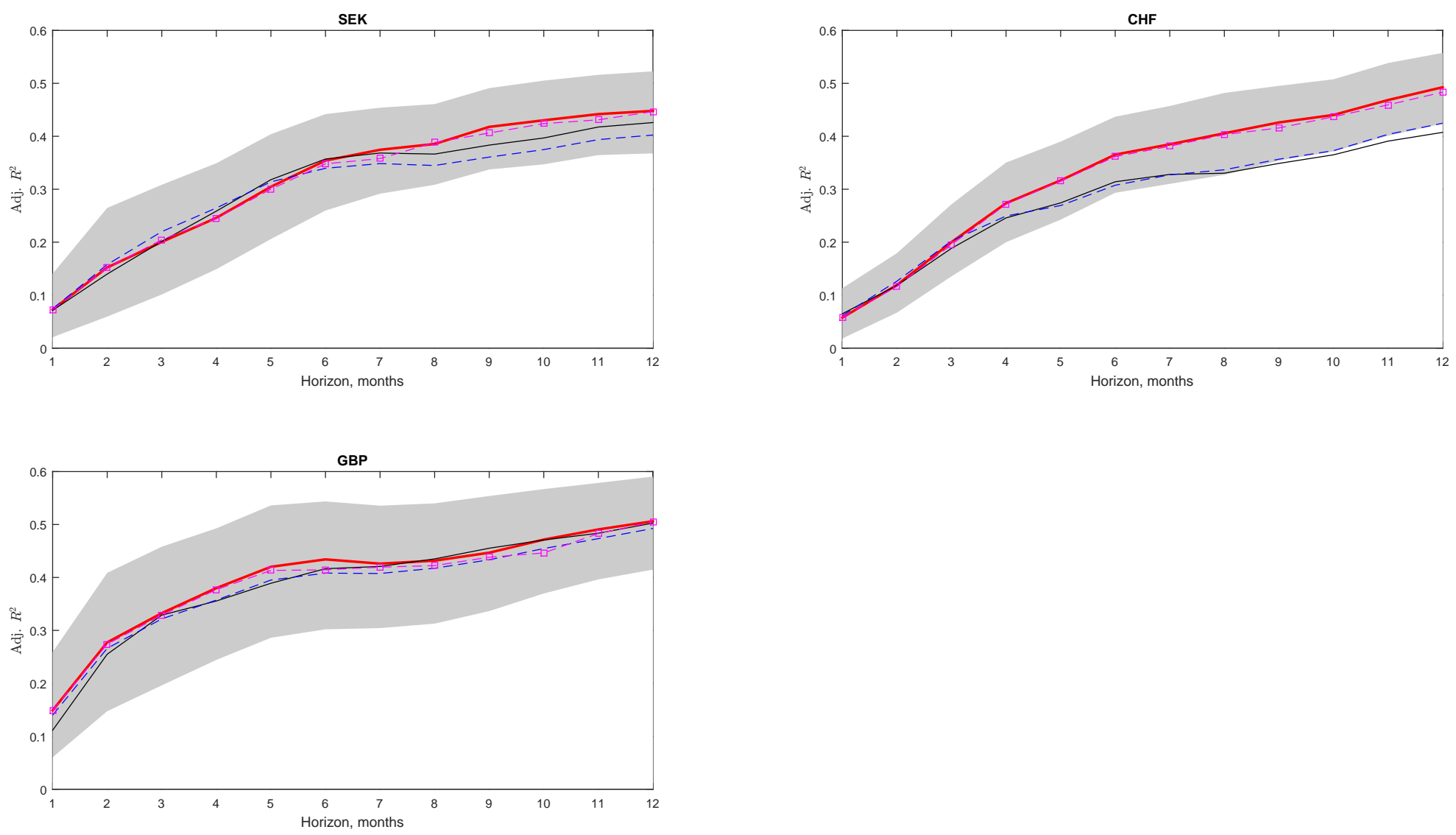

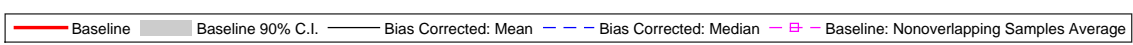




\section{$7 \quad$ Risk Premium and Uncovered Interest Parity}

In order to analyze how different components of the model drive currency returns through the interest rate factors, this section studies the model-implied exchange rates in the context of the Uncovered Interest Parity (UIP) puzzle and the foundational work of Hansen and Hodrick (1980), Fama (1984) and Backus et al. (2001) on risk premium.

UIP suggests that any excess return on foreign-denominated deposits is offset by the expected depreciation against the domestic currency. Empirically, if we ran a regression of the exchange rate changes on the interest rate differential between two countries, we would expect the intercept to be zero and the beta coefficient to be equal to one under UIP. However, the data do not typically hold against this proposition, since the coefficient on the interest rate differential is not only different from one, but also tends to be negative. ${ }^{12}$

In the term structure model-implied exchange rate, unless the prices of risk are zero (i.e., investors are risk neutral), UIP does not hold, since currency depreciations are not only functions of IRDs but also functions of the non-linear RP term and the FSD. I can empirically test whether the UIP condition is satisfied by letting $\Lambda_{t}=\Lambda_{t}^{*}=0$, so that

$$
\Delta s_{t, t+k}^{o b s}=\alpha_{k}+\beta_{1, k} I R D_{t, t+k}+\varepsilon_{t+k} .
$$

Table 6 shows the results of the model-implied relationship between currency returns and IRD when all other components are omitted as in equation (13). The $R^{2}$ in these regressions are around zero for all countries and horizons, suggesting that the IRD component, even at long horizons, is not able to account for the high explanatory power found in table 4. For Australia, Japan, and Switzerland, the beta coefficients are large in absolute value and negative, consistent with the evidence against UIP found in previous work. Norway, Sweden, and the U.K. exhibit positive and negative coefficients for different horizons, with no clear pattern suggesting that UIP holds. Canada is the only case for which the coefficients seem to increase as the horizon is extended during the period considered, although in order to test whether UIP might hold in the long run, horizons beyond one year should be considered. Nevertheless, none of the coefficients are statistically significant and this exercise suggests that the other components in the model must be important to be able to account for about half of one-year currency returns.

Two aspects of the UIP regression are worth noting. First, regression (13) is a slight variation from the traditional UIP regression, since the model-implied IRD is the sum of the risk-free rates and not the

\footnotetext{
${ }^{12}$ Several papers have focused on studying this phenomenon -Burnside et al. (2011) find evidence of UIP failure for a large number of currencies over the 1976-2007 period; and early surveys on the UIP literature can be found in Froot and Thaler (1990) and Lewis (1995). The UIP puzzle has given rise to a prolific literature studying carry trade strategies, by which borrowing low interest rate currencies and lending high interest ones leads to significant profits; see for example work on sorting currencies into portfolios by Lustig and Verdelhan (2007), Lustig et al. (2011), Menkhoff et al. (2012), and Cenedese et al. (2014). More recent studies have identified that UIP holds for some currencies in the long run (Chinn and Meredith, 2004) and that long bond return parity can be explained by nominal exchange rate stationarity (Lustig et al., 2015).
} 
$k$-yield differential. To compare the data and the model, one might consider the data regression $\Delta s_{t, t+\tau}^{o b s}=$ $\alpha_{\tau}+\beta_{\tau}\left(y_{t, \tau}^{o b s}-y_{t, \tau}^{o b s, *}\right)+\mu_{t+\tau}$ and its model-implied counterpart $\Delta s_{t, t+\tau}=\alpha_{\tau}+\beta_{\tau}\left(y_{t, \tau}-y_{t, \tau}^{*}\right)+\mu_{t+\tau}$ for horizons $\tau=\{3 m, 6 m, 1 y\}$. In this case, coefficients are generally statistically insignificant and $R^{2}$ are also close to zero. At least in the time frame considered, UIP does not hold in the data for the AUD/USD, SEK/USD, and CHF/USD. For the remaining currencies, $\beta$ is sometimes positive, although never statistically significant. When results from table 6 are compared to the standard Fama regressions, the signs of the coefficients match the data relatively well, with some exceptions (in particular, the 6 -month CAD/USD and the 12-month JPY/USD, NOK/USD, and GBP/USD).

Second, the presence of the RP term coincides with the most conventional explanation of the UIP failure, attributed to the behavior of a time-varying risk premium component, as rationalized by Fama (1984). In order to derive the risk premium properties that account for the UIP puzzle, consider the forward premium regression as outlined by Backus et al. (2001),

$$
s_{t+1}-s_{t}=a_{1}+a_{2}\left(f_{t}-s_{t}\right)+\text { residual },
$$

who decompose the forward premium $\left(f_{t}-s_{t}\right)$ into the expected rate of depreciation on the dollar, $q_{t}$, and the expected excess return or risk premium, $p_{t}$, where $\left(f_{t}-s_{t}\right)=p_{t}+q_{t} \cdot{ }^{13}$ Backus et al. (2001) specify $q_{t}$ as the expected difference in the log of the SDFs,

$$
q_{t}=\mathbb{E}_{t} s_{t+1}-s_{t}=\mathbb{E}_{t} \log \left(M_{t+1}^{*}\right)-\mathbb{E}_{t} \log \left(M_{t+1}\right),
$$

and define $p_{t}$ as the difference between the log of the expectation and the expectation of the log of the SDFs,

$$
p_{t}=\left(\log \left(\mathbb{E}_{t} M_{t+1}^{*}\right)-\mathbb{E}_{t} \log \left(M_{t+1}^{*}\right)\right)-\left(\log \left(\mathbb{E}_{t} M_{t+1}\right)-\mathbb{E}_{t} \log \left(M_{t+1}\right)\right) .
$$

If conditional moments of all order exist for the log of both SDFs, then for $a_{2}$ to be negative, Fama's necessary conditions for the forward premium anomaly imply:

$$
a_{2}=\frac{\operatorname{cov}(q, p)+\operatorname{var}(q)}{\operatorname{var}(p+q)}<0
$$

(i) $\operatorname{corr}\left(p, r-r^{*}\right)<0:$ A negative correlation between the differences in log SDFs' conditional means and half the differences in conditional variances, and

(ii) $\operatorname{var}(p)>\operatorname{var}(q)$ : Greater variation in half the difference in conditional variances of the SDFs relative

\footnotetext{
${ }^{13}$ The covered parity condition is satisfied as in Backus et al. (2001) and $\left(f_{t}-s_{t}\right)=p_{t}+q_{t}=r_{t}-r_{t}^{*}$.
} 
to the difference in the conditional means.

Table 6: UIP Regression

\begin{tabular}{|c|c|c|c|c|c|c|c|c|c|c|}
\hline Horizon: & & 1-month & 2-month & 3-month & 4-month & 5-month & 6-month & 8-month & 10-month & 12-month \\
\hline \multirow[t]{3}{*}{ AUD } & $\begin{array}{ll}\alpha & \\
& H . H . \\
\beta_{1} & \\
& H . H . \\
& \beta_{1}=1\end{array}$ & $\begin{array}{c}\mathbf{- 0 . 0 0 1} \\
(0.002) \\
\mathbf{- 0 . 2 5 0} \\
(0.662) \\
\langle 0.06\rangle\end{array}$ & $\begin{array}{c}\mathbf{- 0 . 0 0 2} \\
(0.004) \\
\mathbf{- 0 . 2 4 6} \\
(0.594) \\
\langle 0.04\rangle\end{array}$ & $\begin{array}{c}\mathbf{- 0 . 0 0 4} \\
(0.007) \\
\mathbf{- 0 . 2 6 9} \\
(0.524) \\
\langle 0.02\rangle\end{array}$ & $\begin{array}{c}\mathbf{- 0 . 0 0 5} \\
(0.009) \\
\mathbf{- 0 . 2 8 1} \\
(0.500) \\
\langle 0.01\rangle\end{array}$ & $\begin{array}{c}\mathbf{- 0 . 0 0 6} \\
(0.012) \\
\mathbf{- 0 . 2 8 2} \\
(0.506) \\
\langle 0.01\rangle\end{array}$ & $\begin{array}{c}\mathbf{- 0 . 0 0 7} \\
(0.014) \\
\mathbf{- 0 . 2 8 2} \\
(0.507) \\
\langle 0.01\rangle\end{array}$ & $\begin{array}{c}\mathbf{- 0 . 0 0 9} \\
(0.018) \\
\mathbf{- 0 . 2 9 4} \\
(0.487) \\
\langle 0.01\rangle\end{array}$ & $\begin{array}{c}-\mathbf{0 . 0 1 1} \\
(0.022) \\
-\mathbf{0 . 3 0 1} \\
(0.502) \\
\langle 0.01\rangle\end{array}$ & $\begin{array}{c}-\mathbf{0 . 0 1 4} \\
(0.026) \\
-\mathbf{0 . 3 1 0} \\
(0.524) \\
\langle 0.01\rangle\end{array}$ \\
\hline & $\alpha=0, \beta_{1}=1$ & $\langle 0.16\rangle$ & $\langle 0.10\rangle$ & $\langle 0.03\rangle$ & $\langle 0.01\rangle$ & $\langle 0.01\rangle$ & $\langle 0.01\rangle$ & $\langle 0.01\rangle$ & $\langle 0.01\rangle$ & $\langle 0.02\rangle$ \\
\hline & $R^{2}$ & -0.00 & -0.00 & -0.00 & -0.00 & -0.00 & -0.00 & 0.00 & 0.00 & 0.00 \\
\hline \multirow[t]{3}{*}{$\mathrm{CAD}$} & $\begin{array}{ll}\alpha & \\
& H . H . \\
\beta_{1} & \\
& H . H . \\
& \beta_{1}=1\end{array}$ & $\begin{array}{c}\mathbf{- 0 . 0 0 1} \\
(0.001) \\
\mathbf{- 0 . 0 8 4} \\
(0.612) \\
\langle 0.08\rangle\end{array}$ & $\begin{array}{c}\mathbf{- 0 . 0 0 1} \\
(0.003) \\
\mathbf{0 . 1 2 9} \\
(0.665) \\
\langle 0.19\rangle\end{array}$ & $\begin{array}{c}\mathbf{- 0 . 0 0 1} \\
(0.004) \\
\mathbf{0 . 2 2 4} \\
(0.685) \\
\langle 0.26\rangle\end{array}$ & $\begin{array}{c}\mathbf{- 0 . 0 0 1} \\
(0.006) \\
\mathbf{0 . 2 8 9} \\
(0.702) \\
\langle 0.31\rangle\end{array}$ & $\begin{array}{c}\mathbf{- 0 . 0 0 1} \\
(0.007) \\
\mathbf{0 . 3 2 8} \\
(0.730) \\
\langle 0.36\rangle\end{array}$ & $\begin{array}{c}\mathbf{- 0 . 0 0 1} \\
(0.008) \\
\mathbf{0 . 3 7 3} \\
(0.763) \\
\langle 0.41\rangle\end{array}$ & $\begin{array}{c}\mathbf{- 0 . 0 0 1} \\
(0.011) \\
\mathbf{0 . 4 4 6} \\
(0.813) \\
\langle 0.50\rangle\end{array}$ & $\begin{array}{c}\mathbf{- 0 . 0 0 1} \\
(0.013) \\
\mathbf{0 . 4 7 9} \\
(0.855) \\
\langle 0.54\rangle\end{array}$ & $\begin{array}{c}\mathbf{- 0 . 0 0 1} \\
(0.015) \\
\mathbf{0 . 4 9 8} \\
(0.888) \\
\langle 0.57\rangle\end{array}$ \\
\hline & $\alpha=0, \beta_{1}=1$ & $\langle 0.19\rangle$ & $\langle 0.41\rangle$ & $\langle 0.51\rangle$ & $\langle 0.58\rangle$ & $\langle 0.65\rangle$ & $\langle 0.71\rangle$ & $\langle 0.79\rangle$ & $\langle 0.83\rangle$ & $\langle 0.85\rangle$ \\
\hline & $R^{2}$ & -0.00 & -0.00 & -0.00 & -0.00 & -0.00 & -0.00 & 0.00 & 0.00 & 0.00 \\
\hline \multirow[t]{3}{*}{ JPY } & $\begin{array}{ll}\alpha & \\
& H . H . \\
\beta_{1} & \\
& H . H . \\
& \beta_{1}=1\end{array}$ & $\begin{array}{c}\mathbf{0 . 0 0 4} * \\
(0.003) \\
\mathbf{- 0 . 9 7 7} \\
(1.049) \\
\langle 0.06\rangle\end{array}$ & $\begin{array}{c}\mathbf{0 . 0 0 8} \boldsymbol{*} \\
(0.005) \\
\mathbf{- 0 . 9 9 2} \\
(1.102) \\
\langle 0.07\rangle\end{array}$ & $\begin{array}{c}\mathbf{0 . 0 1 1} * \\
(0.008) \\
\mathbf{- 1 . 0 2 7} \\
(1.084) \\
\langle 0.06\rangle\end{array}$ & $\begin{array}{c}\mathbf{0 . 0 1 6}^{*} \\
(0.011) \\
\mathbf{- 1 . 0 9 3} \\
(1.041) \\
\langle 0.04\rangle\end{array}$ & $\begin{array}{c}\mathbf{0 . 0 2 0} \\
(0.013) \\
\mathbf{- 1 . 1 3 1} \\
(1.026) \\
\langle 0.04\rangle\end{array}$ & $\begin{array}{c}\mathbf{0 . 0 2 4} * \\
(0.017) \\
-\mathbf{- 1 . 1 5 1} \\
(1.045) \\
\langle 0.04\rangle\end{array}$ & $\begin{array}{c}\mathbf{0 . 0 3 2} * \\
(0.025) \\
-\mathbf{1 . 1 7 0} \\
(1.121) \\
\langle 0.05\rangle\end{array}$ & $\begin{array}{c}\mathbf{0 . 0 4 0} \\
(0.033) \\
\mathbf{- 1 . 1 8 4} \\
(1.177) \\
\langle 0.06\rangle\end{array}$ & $\begin{array}{c}\mathbf{0 . 0 4 7} \\
(0.041) \\
\mathbf{- 1 . 1 8 1} \\
(1.212) \\
\langle 0.07\rangle\end{array}$ \\
\hline & $\alpha=0, \beta_{1}=1$ & $\langle 0.16\rangle$ & $\langle 0.19\rangle$ & $\langle 0.17\rangle$ & $\langle 0.13\rangle$ & $\langle 0.11\rangle$ & $\langle 0.12\rangle$ & $\langle 0.15\rangle$ & $\langle 0.17\rangle$ & $\langle 0.18\rangle$ \\
\hline & $R^{2}$ & -0.00 & 0.00 & 0.00 & 0.01 & 0.01 & 0.01 & 0.02 & 0.03 & 0.03 \\
\hline \multirow[t]{3}{*}{ NOK } & $\begin{array}{ll}\alpha & \\
& H . H . \\
\beta_{1} & \\
& H . H . \\
& \beta_{1}=1\end{array}$ & $\begin{array}{c}\mathbf{- 0 . 0 0 1} \\
(0.002) \\
\mathbf{0 . 1 2 5} \\
(0.995) \\
\langle 0.38\rangle\end{array}$ & $\begin{array}{c}\mathbf{- 0 . 0 0 1} \\
(0.004) \\
\mathbf{0 . 1 6 3} \\
(0.917) \\
\langle 0.36\rangle\end{array}$ & $\begin{array}{c}\mathbf{- 0 . 0 0 2} \\
(0.006) \\
\mathbf{0 . 1 2 0} \\
(0.777) \\
\langle 0.26\rangle\end{array}$ & $\begin{array}{c}\mathbf{- 0 . 0 0 3} \\
(0.008) \\
\mathbf{0 . 0 5 7} \\
(0.682) \\
\langle 0.17\rangle\end{array}$ & $\begin{array}{c}\mathbf{- 0 . 0 0 5} \\
(0.010) \\
\mathbf{0 . 0 0 2} \\
(0.663) \\
\langle 0.13\rangle\end{array}$ & $\begin{array}{c}\mathbf{- 0 . 0 0 6} \\
(0.012) \\
\mathbf{- 0 . 0 3 9} \\
(0.670) \\
\langle 0.12\rangle\end{array}$ & $\begin{array}{c}\mathbf{- 0 . 0 0 8} \\
(0.015) \\
\mathbf{- 0 . 0 7 4} \\
(0.658) \\
\langle 0.10\rangle\end{array}$ & $\begin{array}{c}-\mathbf{0 . 0 1 0} \\
(0.019) \\
\mathbf{- 0 . 0 8 1} \\
(0.621) \\
\langle 0.08\rangle\end{array}$ & $\begin{array}{c}\mathbf{- 0 . 0 1 2} \\
(0.023) \\
\mathbf{- 0 . 0 8 5} \\
(0.596) \\
\langle 0.07\rangle\end{array}$ \\
\hline & $\alpha=0, \beta_{1}=1$ & $\langle 0.68\rangle$ & $\langle 0.66\rangle$ & $\langle 0.53\rangle$ & $\langle 0.38\rangle$ & $\langle 0.32\rangle$ & $\langle 0.30\rangle$ & $\langle 0.26\rangle$ & $\langle 0.22\rangle$ & $\langle 0.19\rangle$ \\
\hline & $R^{2}$ & -0.00 & -0.00 & -0.00 & -0.00 & -0.00 & -0.00 & -0.00 & -0.00 & -0.00 \\
\hline \multirow[t]{3}{*}{ SEK } & 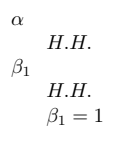 & $\begin{array}{c}\mathbf{- 0 . 0 0 0} \\
(0.002) \\
\mathbf{0 . 0 7 0} \\
(1.129) \\
\langle 0.41\rangle\end{array}$ & $\begin{array}{c}\mathbf{- 0 . 0 0 1} \\
(0.004) \\
\mathbf{0 . 0 1 2} \\
(1.156) \\
\langle 0.39\rangle\end{array}$ & $\begin{array}{c}-0.001 \\
(0.006) \\
-0.036 \\
(1.088) \\
\langle 0.34\rangle\end{array}$ & $\begin{array}{c}\mathbf{- 0 . 0 0 1} \\
(0.008) \\
\mathbf{- 0 . 0 8 7} \\
(1.027) \\
\langle 0.29\rangle\end{array}$ & $\begin{array}{c}\mathbf{- 0 . 0 0 2} \\
(0.010) \\
\mathbf{- 0 . 1 2 6} \\
(1.018) \\
\langle 0.27\rangle\end{array}$ & $\begin{array}{c}\mathbf{- 0 . 0 0 2} \\
(0.012) \\
\mathbf{- 0 . 1 6 5} \\
(1.025) \\
\langle 0.26\rangle\end{array}$ & $\begin{array}{c}\mathbf{- 0 . 0 0 3} \\
(0.015) \\
\mathbf{- 0 . 2 1 8} \\
(1.004) \\
\langle 0.23\rangle\end{array}$ & $\begin{array}{c}\mathbf{- 0 . 0 0 4} \\
(0.019) \\
\mathbf{- 0 . 2 4 3} \\
(0.967) \\
\langle 0.20\rangle\end{array}$ & $\begin{array}{c}\mathbf{- 0 . 0 0 5} \\
(0.023) \\
\mathbf{- 0 . 2 4 9} \\
(0.945) \\
\langle 0.19\rangle\end{array}$ \\
\hline & $\alpha=0, \beta_{1}=1$ & $\langle 0.68\rangle$ & $\langle 0.67\rangle$ & $\langle 0.61\rangle$ & $\langle 0.55\rangle$ & $\langle 0.52\rangle$ & $\langle 0.50\rangle$ & $\langle 0.46\rangle$ & $\langle 0.41\rangle$ & $\langle 0.39\rangle$ \\
\hline & $R^{2}$ & -0.00 & -0.00 & -0.00 & -0.00 & -0.00 & -0.00 & -0.00 & 0.00 & 0.00 \\
\hline \multirow[t]{3}{*}{$\mathrm{CHF}$} & 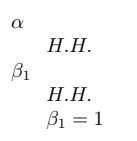 & $\begin{array}{c}\mathbf{0 . 0 0 2} \\
(0.002) \\
\mathbf{- 0 . 9 7 1} \\
(1.025) \\
\langle 0.05\rangle\end{array}$ & $\begin{array}{c}\mathbf{0 . 0 0 4} \\
(0.005) \\
\mathbf{- 0 . 9 6 2} \\
(0.975) \\
\langle 0.04\rangle\end{array}$ & $\begin{array}{c}\mathbf{0 . 0 0 6} \\
(0.006) \\
\mathbf{- 1 . 0 0 4} \\
(0.814) \\
\langle 0.01\rangle\end{array}$ & $\begin{array}{c}\mathbf{0 . 0 0 8} \\
(0.007) \\
\mathbf{- 0 . 9 8 8} \\
(0.679) \\
\langle 0.00\rangle\end{array}$ & $\begin{array}{c}\mathbf{0 . 0 1 0} \\
(0.009) \\
\mathbf{- 0 . 9 5 2} \\
(0.640) \\
\langle 0.00\rangle\end{array}$ & $\begin{array}{c}\mathbf{0 . 0 1 2} \\
(0.010) \\
\mathbf{- 0 . 9 0 4} \\
(0.655) \\
\langle 0.00\rangle\end{array}$ & $\begin{array}{c}\mathbf{0 . 0 1 6} \\
(0.013) \\
\mathbf{- 0 . 8 1 2} \\
(0.663) \\
\langle 0.01\rangle\end{array}$ & $\begin{array}{c}\text { 0.020* } \\
(0.015) \\
\mathbf{- 0 . 7 8 9} \\
(0.619) \\
\langle 0.00\rangle\end{array}$ & $\begin{array}{c}\mathbf{0 . 0 2 4}^{*} \\
(0.016) \\
\mathbf{- 0 . 8 0 6} \\
(0.618) \\
\langle 0.00\rangle\end{array}$ \\
\hline & $\alpha=0, \beta_{1}=1$ & $\langle 0.13\rangle$ & $\langle 0.10\rangle$ & $\langle 0.04\rangle$ & $\langle 0.01\rangle$ & $\langle 0.01\rangle$ & $\langle 0.01\rangle$ & $\langle 0.02\rangle$ & $\langle 0.01\rangle$ & $\langle 0.01\rangle$ \\
\hline & $R^{2}$ & 0.00 & 0.01 & 0.01 & 0.01 & 0.02 & 0.02 & 0.02 & 0.03 & 0.03 \\
\hline \multirow[t]{3}{*}{ GBP } & 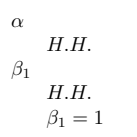 & $\begin{array}{c}\mathbf{- 0 . 0 0 1} \\
(0.002) \\
\mathbf{0 . 1 0 7} \\
(1.620) \\
\langle 0.58\rangle\end{array}$ & $\begin{array}{c}\mathbf{- 0 . 0 0 1} \\
(0.004) \\
\mathbf{0 . 1 7 0} \\
(1.555) \\
\langle 0.59\rangle\end{array}$ & $\begin{array}{c}\mathbf{- 0 . 0 0 1} \\
(0.005) \\
\mathbf{0 . 1 6 5} \\
(1.410) \\
\langle 0.55\rangle\end{array}$ & $\begin{array}{c}\mathbf{- 0 . 0 0 1} \\
(0.007) \\
\mathbf{0 . 1 3 3} \\
(1.324) \\
\langle 0.51\rangle\end{array}$ & $\begin{array}{c}\mathbf{- 0 . 0 0 2} \\
(0.008) \\
\mathbf{0 . 0 7 6} \\
(1.250) \\
\langle 0.46\rangle\end{array}$ & $\begin{array}{c}\mathbf{- 0 . 0 0 2} \\
(0.009) \\
\mathbf{0 . 0 3 0} \\
(1.169) \\
\langle 0.41\rangle\end{array}$ & $\begin{array}{c}\mathbf{- 0 . 0 0 2} \\
(0.010) \\
\mathbf{- 0 . 0 3 1} \\
(0.973) \\
\langle 0.29\rangle\end{array}$ & $\begin{array}{c}-0.003 \\
(0.012) \\
-0.096 \\
(0.798) \\
\langle 0.17\rangle\end{array}$ & $\begin{array}{c}-0.005 \\
(0.015) \\
-\mathbf{0 . 1 6 4} \\
(0.778) \\
\langle 0.13\rangle\end{array}$ \\
\hline & $\alpha=0, \beta_{1}=1$ & $\langle 0.86\rangle$ & $\langle 0.87\rangle$ & $\langle 0.83\rangle$ & $\langle 0.80\rangle$ & $\langle 0.75\rangle$ & $\langle 0.70\rangle$ & $\langle 0.57\rangle$ & $\langle 0.39\rangle$ & $\langle 0.33\rangle$ \\
\hline & $R^{2}$ & -0.00 & -0.00 & -0.00 & -0.00 & -0.00 & -0.00 & -0.00 & -0.00 & -0.00 \\
\hline
\end{tabular}

Notes: Estimates for $\Delta s_{t, t+k}^{o b s}=\alpha_{k}+\beta_{1, k} I R D_{t, t+k}+\varepsilon_{t+k}$, where $\Delta s_{t, t+k}^{o b s}$ is the observed log exchange rate change in USD between $t$ and $t+k$ and the interest rate differential is $I R D_{t, t+k} \equiv \sum_{j=1}^{k}\left(r_{t+j-1}-r_{t+j-1}^{*}\right)$, where the domestic country is the U.S. and the foreign country is $*$. H.H. refers to Hansen-Hodrick standard errors, where the lag is equal to the horizon $k+1$ (in months). The significance level of the coefficients is determined by $\left({ }^{*}\right)$ where $*^{* *} \mathrm{p}<0.01,{ }^{* *}$ $\mathrm{p}<0.05, * \mathrm{p}<0.1$. Several null hypotheses are tested and $\mathrm{p}$-values are reported in \langle\rangle$. R^{2}$ is adjusted by degrees of freedom. 
For the domestic country, this implies that $\mu_{1 t}=-\left(\Lambda_{1}^{\prime} \Sigma^{-1^{\prime}} \Sigma^{-1} \Lambda_{1}\right)^{-1}\left(\rho_{1}^{\prime}+\Lambda_{0}^{\prime} \Sigma^{-1^{\prime}} \Sigma^{-1} \Lambda_{1}\right)$ and $\mu_{2 t}=$ $\left(\Lambda_{1}^{\prime} \Sigma^{-1^{\prime}} \Sigma^{-1} \Lambda_{1}\right)^{-1}$, and similarly for the foreign country, so that

$$
p_{t}=\frac{1}{2}\left(\mu_{2 t}^{*}-\mu_{2 t}\right) \quad \text { and } \quad q_{t}=\mu_{1 t}^{*}-\mu_{1 t}
$$

From the following,

$$
\begin{gathered}
\mu_{1 t}^{*}-\mu_{1 t}=\left(\Lambda_{1}^{\prime} \Sigma^{-1^{\prime}} \Sigma^{-1} \Lambda_{1}\right)^{-1}\left(\rho_{1}^{\prime}+\Lambda_{0}^{\prime} \Sigma^{-1^{\prime}} \Sigma^{-1} \Lambda_{1}\right)-\left(\Lambda_{1}^{*^{\prime}} \Sigma^{*-1^{\prime}} \Sigma^{*-1} \Lambda_{1}^{*}\right)^{-1}\left(\rho_{1}^{*^{\prime}}+\Lambda_{0}^{*^{\prime}} \Sigma^{*-1^{\prime}} \Sigma^{*-1} \Lambda_{1}^{*}\right) \\
\frac{1}{2}\left(\mu_{2 t}^{*}-\mu_{2 t}\right)=\frac{1}{2}\left(\Lambda_{1}^{*^{\prime}} \Sigma^{*-1^{\prime}} \Sigma^{*-1} \Lambda_{1}^{*}\right)^{-1}-\frac{1}{2}\left(\Lambda_{1}^{\prime} \Sigma^{-1^{\prime}} \Sigma^{-1} \Lambda_{1}\right)^{-1}
\end{gathered}
$$

condition $(i)$ is satisfied since the model implies an inverse relationship between the difference in the conditional means $\left(\mu_{1 t}, \mu_{1 t}^{*}\right)$ and the difference in the conditional variances $\left(\mu_{2 t}, \mu_{2 t}^{*}\right)$ of the SDFs. Condition $(i i)$ is satisfied when

$$
\frac{\left(\Lambda_{1}^{\prime} \Sigma^{-1^{\prime}} \Sigma^{-1} \Lambda_{1}\right)}{\left(\Lambda_{1}^{*^{\prime}} \Sigma^{*-1^{\prime}} \Sigma^{*-1} \Lambda_{1}^{*}\right)}>\frac{\left(\frac{1}{2}+\rho_{1}^{\prime}+\Lambda_{0}^{\prime} \Sigma^{-1^{\prime}} \Sigma^{-1} \Lambda_{1}\right)}{\left(\frac{1}{2}+\rho_{1}^{*^{\prime}}+\Lambda_{0}^{*^{\prime}} \Sigma^{*-1^{\prime}} \Sigma^{*-1} \Lambda_{1}^{*}\right)} .
$$

Empirically, the Fama conditions hold for all currencies and for all horizons considered, except for Canada's long-run model-implied currency returns. The variance of the RP is significantly higher than the variance of the IRD. Also, the correlation between the model-implied interest rate differential and risk premium is always negative and gets larger as the horizon increases. Given that the IRD cannot justify fluctuations in the exchange rate and that the RP component is consistent with the properties that account for the empirical failure of UIP, I further examine the role of the RP in my model.

In order to empirically analyze the importance of the different components in the model, tables 7 (a) and 7 (b) present the results of regression (14), which incorporate the RP and FSD components as suggested by the model,

$$
\Delta s_{t, t+k}^{o b s}=\alpha_{k}+\beta_{1, k} I R D_{t, t+k}+\beta_{2, k} R P_{t, t+k}+\beta_{3, k} F S D_{t, t+k}+\nu_{t+k}
$$

where each term is defined as in equation (11). Notice that the $R^{2}$ are either the same as in table 4 or slightly higher, but this specification allows one to also observe the contribution of each model component towards fitting the exchange rate. The intercept in regression (14) is typically zero and statistically insignificant. $\beta_{1}$, in this new specification, tends to be positive, although usually statistically insignificant. Consistent with the explanation that UIP failure is due to a time-varying risk premium that satisfies the Fama conditions, most negative coefficients become positive after the other terms are incorporated and at longer horizons the 
slope coefficients are restored to around one. The two exceptions are Canada and the U.K.

Table 7 (a): Components of Exchange Rate Model

\begin{tabular}{|c|c|c|c|c|c|c|c|c|c|c|}
\hline Horizon: & & 1-month & 2-month & 3-month & 4-month & 5-month & 6-month & 8-month & 10-month & 12-month \\
\hline \multirow[t]{3}{*}{ AUD } & $\begin{array}{cc}\alpha & \\
& H . H . \\
\beta_{1} & \\
& H . H . \\
\beta_{2} & \\
& \text { H.H. } \\
\beta_{3} & \\
& \text { H.H. }\end{array}$ & $\begin{array}{c}\mathbf{- 0 . 0 0 1} \\
(0.002) \\
\mathbf{0 . 2 6 9} \\
(0.565) \\
\mathbf{0 . 6 0 7 * * *} \\
(0.213) \\
\mathbf{0 . 4 1 0 * * *} \\
(0.113)\end{array}$ & $\begin{array}{c}\mathbf{- 0 . 0 0 2} \\
(0.003) \\
\mathbf{0 . 3 3 2} \\
(0.456) \\
\mathbf{0 . 6 9 3} * * * \\
(0.192) \\
\mathbf{0 . 5 3 0 * * *} \\
(0.122)\end{array}$ & $\begin{array}{c}\mathbf{- 0 . 0 0 3} \\
(0.005) \\
\mathbf{0 . 3 6 3} \\
(0.465) \\
\mathbf{0 . 7 9 7 * * *} \\
(0.194) \\
\mathbf{0 . 6 9 9 * * *} \\
(0.146)\end{array}$ & $\begin{array}{c}\mathbf{- 0 . 0 0 4} \\
(0.007) \\
\mathbf{0 . 3 8 8} \\
(0.471) \\
\mathbf{0 . 8 7 4 * * *} \\
(0.193) \\
\mathbf{0 . 8 3 0 * * *} \\
(0.171)\end{array}$ & $\begin{array}{c}\mathbf{- 0 . 0 0 5} \\
(0.009) \\
\mathbf{0 . 4 1 3} \\
(0.443) \\
\mathbf{0 . 9 2 5 * * *} \\
(0.192) \\
\mathbf{0 . 8 8 0 ^ { * * * }} \\
(0.182)\end{array}$ & $\begin{array}{c}\mathbf{- 0 . 0 0 6} \\
(0.010) \\
\mathbf{0 . 4 3 5} \\
(0.404) \\
\mathbf{0 . 9 6 3} * * * \\
(0.190) \\
\mathbf{0 . 9 0 8 * * *} \\
(0.190)\end{array}$ & 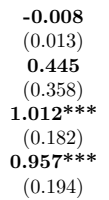 & $\begin{array}{c}\mathbf{- 0 . 0 1 0} \\
(0.015) \\
\mathbf{0 . 4 5 9 *} \\
(0.353) \\
\mathbf{1 . 0 2 2} * * * \\
(0.162) \\
\mathbf{0 . 9 5 5 * * *} \\
(0.175)\end{array}$ & $\begin{array}{c}\mathbf{- 0 . 0 1 2} \\
(0.016) \\
\mathbf{0 . 4 6 9 *} \\
(0.360) \\
\mathbf{1 . 0 1 2 * * *} \\
(0.147) \\
\mathbf{0 . 9 1 5 * *} \\
(0.161)\end{array}$ \\
\hline & $\begin{array}{l}R^{2} \\
{\left[R_{L}^{2}, R_{H}^{2}\right]}\end{array}$ & $\begin{array}{c}0.06 \\
{[0.02,0.11]}\end{array}$ & $\begin{array}{c}0.11 \\
{[0.06,0.18]}\end{array}$ & $\begin{array}{c}0.21 \\
{[0.14,0.28]}\end{array}$ & $\begin{array}{c}0.29 \\
{[0.22,0.37]}\end{array}$ & $\begin{array}{c}0.34 \\
{[0.26,0.42]}\end{array}$ & $\begin{array}{c}0.37 \\
{[0.30,0.45]}\end{array}$ & $\begin{array}{c}0.42 \\
{[0.36,0.49]}\end{array}$ & $\begin{array}{c}0.45 \\
{[0.39,0.51]}\end{array}$ & $\begin{array}{c}0.45 \\
{[0.39,0.50]}\end{array}$ \\
\hline & $\begin{array}{l}\operatorname{Mean}\left(\mu_{t}\right) \\
\text { Std. Err. }\left(\mu_{t}\right)\end{array}$ & $\begin{array}{l}0.000 \\
0.033\end{array}$ & $\begin{array}{c}-0.000 \\
0.047\end{array}$ & $\begin{array}{l}0.000 \\
0.055\end{array}$ & $\begin{array}{c}-0.000 \\
0.061\end{array}$ & $\begin{array}{l}0.000 \\
0.066\end{array}$ & $\begin{array}{l}0.000 \\
0.070\end{array}$ & $\begin{array}{l}0.000 \\
0.078\end{array}$ & $\begin{array}{c}-0.000 \\
0.085\end{array}$ & $\begin{array}{l}0.000 \\
0.093\end{array}$ \\
\hline \multirow[t]{3}{*}{ CAD } & $\begin{array}{cc}\alpha & \\
& H . H . \\
\beta_{1} & \\
& H . H . \\
\beta_{2} & \\
& H . H . \\
\beta_{3} & \\
& \text { H.H. }\end{array}$ & $\begin{array}{c}-\mathbf{0 . 0 0 1} \\
(0.001) \\
\mathbf{- 0 . 5 6 5} \\
(0.673) \\
\mathbf{- 1 . 2 7 2} \\
(0.979) \\
\mathbf{0 . 0 9 1} \\
(0.150)\end{array}$ & $\begin{array}{c}\mathbf{- 0 . 0 0 1} \\
(0.003) \\
\mathbf{- 0 . 2 3 0} \\
(0.639) \\
\mathbf{- 0 . 8 3 5} \\
(0.647) \\
\mathbf{0 . 3 7 7 ^ { * * }} \\
(0.162)\end{array}$ & $\begin{array}{c}-\mathbf{- 0 . 0 0 2} \\
(0.004) \\
\mathbf{- 0 . 1 3 2} \\
(0.640) \\
\mathbf{- 0 . 7 4 7} \\
(0.703) \\
\mathbf{0 . 4 5 0 * * *} \\
(0.180)\end{array}$ & $\begin{array}{c}-\mathbf{0 . 0 0 2} \\
(0.005) \\
\mathbf{0 . 0 0 6} \\
(0.628) \\
\mathbf{- 0 . 5 2 0} \\
(0.675) \\
\mathbf{0 . 5 6 8 * * *} \\
(0.197)\end{array}$ & $\begin{array}{c}-\mathbf{- 0 . 0 0 2} \\
(0.006) \\
\mathbf{0 . 0 4 0} \\
(0.623) \\
\mathbf{- 0 . 3 8 0} \\
(0.683) \\
\mathbf{0 . 6 6 6 * * *} \\
(0.214)\end{array}$ & $\begin{array}{c}\mathbf{- 0 . 0 0 2} \\
(0.006) \\
\mathbf{0 . 1 0 2} \\
(0.617) \\
\mathbf{- 0 . 1 3 5} \\
(0.667) \\
\mathbf{0 . 7 8 5 * * *} \\
(0.227)\end{array}$ & $\begin{array}{c}\mathbf{- 0 . 0 0 2} \\
(0.008) \\
\mathbf{0 . 1 4 8} \\
(0.627) \\
\mathbf{0 . 1 3 3} \\
(0.677) \\
\mathbf{0 . 9 1 3 * * *} \\
(0.206)\end{array}$ & $\begin{array}{c}\mathbf{- 0 . 0 0 1} \\
(0.010) \\
\mathbf{0 . 2 5 2} \\
(0.614) \\
\mathbf{0 . 5 2 9} \\
(0.642) \\
\mathbf{1 . 0 7 1 * * *} \\
(0.197)\end{array}$ & $\begin{array}{c}\mathbf{- 0 . 0 0 1} \\
(0.012) \\
\mathbf{0 . 2 4 2} \\
(0.609) \\
\mathbf{0 . 7 8 8 ^ { * }} \\
(0.606) \\
\mathbf{1 . 2 1 6 * * *} \\
(0.201)\end{array}$ \\
\hline & $\begin{array}{l}R^{2} \\
{\left[R_{L}^{2}, R_{H}^{2}\right]}\end{array}$ & $\begin{array}{c}0.00 \\
{[-0.01,0.05]}\end{array}$ & $\begin{array}{c}0.07 \\
{[0.01,0.17]}\end{array}$ & $\begin{array}{c}0.10 \\
{[0.04,0.19]}\end{array}$ & $\begin{array}{c}0.16 \\
{[0.08,0.26]}\end{array}$ & $\begin{array}{c}0.20 \\
{[0.12,0.30]}\end{array}$ & $\begin{array}{c}0.26 \\
{[0.18,0.35]}\end{array}$ & $\begin{array}{c}0.32 \\
{[0.25,0.40]}\end{array}$ & $\begin{array}{c}0.40 \\
{[0.32,0.48]}\end{array}$ & $\begin{array}{c}0.47 \\
{[0.40,0.55]}\end{array}$ \\
\hline & $\begin{array}{l}\operatorname{Mean}\left(\mu_{t}\right) \\
\text { Std. Err. }\left(\mu_{t}\right)\end{array}$ & $\begin{array}{l}0.000 \\
0.023\end{array}$ & $\begin{array}{c}-0.000 \\
0.030\end{array}$ & $\begin{array}{c}-0.000 \\
0.036\end{array}$ & $\begin{array}{l}0.000 \\
0.040\end{array}$ & $\begin{array}{l}0.000 \\
0.045\end{array}$ & $\begin{array}{c}-0.000 \\
0.048\end{array}$ & $\begin{array}{c}-0.000 \\
0.053\end{array}$ & $\begin{array}{c}-0.000 \\
0.056\end{array}$ & $\begin{array}{l}0.000 \\
0.058\end{array}$ \\
\hline \multirow[t]{3}{*}{ JPY } & $\begin{array}{cc}\alpha & \\
& H . H . \\
\beta_{1} & \\
& H . H . \\
\beta_{2} & \\
& \text { H.H. } \\
\beta_{3} & \\
& \text { H.H. }\end{array}$ & $\begin{array}{c}\mathbf{0 . 0 0 0} \\
(0.002) \\
\mathbf{0 . 6 0 0} \\
(1.024) \\
\mathbf{0 . 9 8 8 * * *} \\
(0.260) \\
\mathbf{0 . 3 0 5 * * *} \\
(0.118)\end{array}$ & $\begin{array}{c}\mathbf{0 . 0 0 0} \\
(0.004) \\
\mathbf{0 . 7 0 5} \\
(1.046) \\
\mathbf{1 . 0 5 5 * * *} \\
(0.276) \\
\mathbf{0 . 4 3 0 * * *} \\
(0.125)\end{array}$ & $\begin{array}{c}\mathbf{0 . 0 0 0} \\
(0.006) \\
\mathbf{0 . 7 5 1} \\
(1.005) \\
\mathbf{1 . 0 6 8 * * *} \\
(0.263) \\
\mathbf{0 . 6 1 8 * * *} \\
(0.125)\end{array}$ & $\begin{array}{c}\mathbf{0 . 0 0 1} \\
(0.008) \\
\mathbf{0 . 7 5 8} \\
(0.935) \\
\mathbf{1 . 0 7 5 * * *} \\
(0.227) \\
\mathbf{0 . 7 2 1 * * *} \\
(0.111)\end{array}$ & $\begin{array}{c}\mathbf{0 . 0 0 0} \\
(0.010) \\
\mathbf{0 . 8 0 3} \\
(0.896) \\
\mathbf{1 . 0 9 3 * * *} \\
(0.206) \\
\mathbf{0 . 7 8 2 * * *} \\
(0.102)\end{array}$ & $\begin{array}{c}\mathbf{- 0 . 0 0 0} \\
(0.012) \\
\mathbf{0 . 8 6 5} \\
(0.897) \\
\mathbf{1 . 1 1 1 * * *} \\
(0.205) \\
\mathbf{0 . 8 5 3} * * * \\
(0.117)\end{array}$ & $\begin{array}{c}\mathbf{- 0 . 0 0 2} \\
(0.016) \\
\mathbf{0 . 9 9 8} \\
(0.939) \\
\mathbf{1 . 1 5 1 ^ { * * * }} \\
(0.225) \\
\mathbf{0 . 8 5 3 * * *} \\
(0.122)\end{array}$ & $\begin{array}{c}\mathbf{- 0 . 0 0 4} \\
(0.020) \\
\mathbf{1 . 0 5 4} \\
(0.973) \\
\mathbf{1 . 1 5 4 * * *} \\
(0.241) \\
\mathbf{0 . 8 5 6 * * *} \\
(0.139)\end{array}$ & $\begin{array}{c}\mathbf{- 0 . 0 0 6} \\
(0.024) \\
\mathbf{1 . 0 8 6} \\
(0.990) \\
\mathbf{1 . 1 3 0 * * *} \\
(0.254) \\
\mathbf{0 . 9 2 7 * * *} \\
(0.168)\end{array}$ \\
\hline & $\begin{array}{l}R^{2} \\
{\left[R_{L}^{2}, R_{H}^{2}\right]}\end{array}$ & $\begin{array}{c}0.06 \\
{[0.03,0.12]}\end{array}$ & $\begin{array}{c}0.14 \\
{[0.09,0.21]}\end{array}$ & $\begin{array}{c}0.21 \\
{[0.15,0.29]}\end{array}$ & $\begin{array}{c}0.27 \\
{[0.21,0.35]}\end{array}$ & $\begin{array}{c}0.32 \\
{[0.26,0.39]}\end{array}$ & $\begin{array}{c}0.38 \\
{[0.31,0.45]}\end{array}$ & $\begin{array}{c}0.46 \\
{[0.39,0.53]}\end{array}$ & $\begin{array}{c}0.50 \\
{[0.43,0.57]}\end{array}$ & $\begin{array}{c}0.53 \\
{[0.47,0.59]}\end{array}$ \\
\hline & $\begin{array}{l}\operatorname{Mean}\left(\mu_{t}\right) \\
\text { Std. Err. }\left(\mu_{t}\right)\end{array}$ & $\begin{array}{l}0.000 \\
0.031\end{array}$ & $\begin{array}{l}0.000 \\
0.043\end{array}$ & $\begin{array}{l}0.000 \\
0.053\end{array}$ & $\begin{array}{c}-0.000 \\
0.060\end{array}$ & $\begin{array}{c}-0.000 \\
0.066\end{array}$ & $\begin{array}{c}-0.000 \\
0.069\end{array}$ & $\begin{array}{c}-0.000 \\
0.073\end{array}$ & $\begin{array}{c}-0.000 \\
0.079\end{array}$ & $\begin{array}{l}0.000 \\
0.087\end{array}$ \\
\hline \multirow[t]{3}{*}{ NOK } & $\begin{array}{cc}\alpha & \\
& H . H . \\
\beta_{1} & \\
& \text { H.H. } \\
\beta_{2} & \\
& \text { H.H. } \\
\beta_{3} & \text { H.H. } \\
& \text { H.H. }\end{array}$ & $\begin{array}{c}\mathbf{- 0 . 0 0 1} \\
(0.002) \\
\mathbf{0 . 7 0 8} \\
(0.580) \\
\mathbf{0 . 7 7 4 * * *} \\
(0.216) \\
\mathbf{0 . 4 3 8 * * *} \\
(0.145)\end{array}$ & $\begin{array}{c}-\mathbf{- 0 . 0 0 2} \\
(0.003) \\
\mathbf{0 . 6 9 3} \\
(0.533) \\
\mathbf{0 . 8 3 4} 4^{* * *} \\
(0.212) \\
\mathbf{0 . 6 3 4} 4^{* * *} \\
(0.133)\end{array}$ & $\begin{array}{c}-\mathbf{- 0 . 0 0 3} \\
(0.004) \\
\mathbf{0 . 7 0 9 *} \\
(0.494) \\
\mathbf{0 . 8 9 6 * * *} \\
(0.205) \\
\mathbf{0 . 7 2 5 * * *} \\
(0.158)\end{array}$ & $\begin{array}{c}-\mathbf{0 . 0 0 4} \\
(0.006) \\
\mathbf{0 . 6 7 0 *} \\
(0.489) \\
\mathbf{0 . 9 3 4 * * *} \\
(0.200) \\
\mathbf{0 . 8 2 9 * * *} \\
(0.183)\end{array}$ & $\begin{array}{c}\mathbf{- 0 . 0 0 6} \\
(0.007) \\
\mathbf{0 . 6 9 5} \\
(0.490) \\
\mathbf{0 . 9 8 1 * * *} \\
(0.207) \\
\mathbf{0 . 8 5 7 * * *} \\
(0.197)\end{array}$ & $\begin{array}{c}\mathbf{- 0 . 0 0 7} \\
(0.008) \\
\mathbf{0 . 7 2 5 *} \\
(0.475) \\
\mathbf{1 . 0 2 0 * * *} \\
(0.211) \\
\mathbf{0 . 8 7 0 * * *} \\
(0.193)\end{array}$ & $\begin{array}{c}\mathbf{- 0 . 0 0 8} \\
(0.010) \\
\mathbf{0 . 8 8 3} * * \\
(0.434) \\
\mathbf{1 . 0 8 7 * * *} \\
(0.219) \\
\mathbf{0 . 7 7 3 * * *} \\
(0.185)\end{array}$ & $\begin{array}{c}\mathbf{- 0 . 0 1 0} \\
(0.011) \\
\mathbf{1 . 0 2 9 * * *} \\
(0.414) \\
\mathbf{1 . 1 5 3 * * *} \\
(0.218) \\
\mathbf{0 . 7 2 9 * * *} \\
(0.164)\end{array}$ & $\begin{array}{c}\mathbf{- 0 . 0 1 2} \\
(0.014) \\
\mathbf{1 . 1 4 8 * * *} \\
(0.400) \\
\mathbf{1 . 2 0 7 * * *} \\
(0.219) \\
\mathbf{0 . 6 9 1 * * *} \\
(0.156)\end{array}$ \\
\hline & $\begin{array}{l}R^{2} \\
{\left[R_{L}^{2}, R_{H}^{2}\right]}\end{array}$ & $\begin{array}{c}0.09 \\
{[0.05,0.16]}\end{array}$ & $\begin{array}{c}0.20 \\
{[0.12,0.28]}\end{array}$ & $\begin{array}{c}0.26 \\
{[0.18,0.35]}\end{array}$ & $\begin{array}{c}0.32 \\
{[0.24,0.40]}\end{array}$ & $\begin{array}{c}0.35 \\
{[0.27,0.43]}\end{array}$ & $\begin{array}{c}0.37 \\
{[0.30,0.45]}\end{array}$ & $\begin{array}{c}0.38 \\
{[0.31,0.45]}\end{array}$ & $\begin{array}{c}0.42 \\
{[0.35,0.50]}\end{array}$ & $\begin{array}{c}0.46 \\
{[0.38,0.53]}\end{array}$ \\
\hline & $\begin{array}{l}\operatorname{Mean}\left(\mu_{t}\right) \\
\text { Std. Err. }\left(\mu_{t}\right)\end{array}$ & $\begin{array}{c}-0.000 \\
0.030\end{array}$ & $\begin{array}{l}0.000 \\
0.042\end{array}$ & $\begin{array}{l}0.000 \\
0.050\end{array}$ & $\begin{array}{l}0.000 \\
0.057\end{array}$ & $\begin{array}{l}0.000 \\
0.063\end{array}$ & $\begin{array}{l}0.000 \\
0.067\end{array}$ & $\begin{array}{l}0.000 \\
0.077\end{array}$ & $\begin{array}{l}0.000 \\
0.081\end{array}$ & $\begin{array}{c}-0.000 \\
0.085\end{array}$ \\
\hline \multirow[t]{3}{*}{ SEK } & $\begin{array}{cc}\alpha & \\
& H . H . \\
\beta_{1} & \\
& H . H . \\
\beta_{2} & \\
& \text { H.H. } \\
\beta_{3} & \\
& \text { H.H. }\end{array}$ & $\begin{array}{c}\mathbf{0 . 0 0 0} \\
(0.002) \\
\mathbf{0 . 1 7 2} \\
(0.870) \\
\mathbf{0 . 3 1 5} \\
(0.474) \\
\mathbf{0 . 3 1 0 ^ { * * * }} \\
(0.057)\end{array}$ & $\begin{array}{c}\mathbf{0 . 0 0 1} \\
(0.004) \\
\mathbf{0 . 2 8 7} \\
(0.872) \\
\mathbf{0 . 4 4 4} \\
(0.507) \\
\mathbf{0 . 4 8 2 * * *} \\
(0.106)\end{array}$ & $\begin{array}{c}\mathbf{0 . 0 0 2} \\
(0.006) \\
\mathbf{0 . 4 0 1} \\
(0.825) \\
\mathbf{0 . 5 5 2} \\
(0.540) \\
\mathbf{0 . 5 9 3 * * *} \\
(0.125)\end{array}$ & $\begin{array}{c}\mathbf{0 . 0 0 5} \\
(0.008) \\
\mathbf{0 . 5 1 9} \\
(0.793) \\
\mathbf{0 . 6 6 1} \\
(0.548) \\
\mathbf{0 . 7 2 3 * * *} \\
(0.161)\end{array}$ & $\begin{array}{c}\mathbf{0 . 0 0 8} \\
(0.010) \\
\mathbf{0 . 6 8 5} \\
(0.780) \\
\mathbf{0 . 8 2 4}^{*} \\
(0.525) \\
\mathbf{0 . 8 5 1 * * *} \\
(0.172)\end{array}$ & $\begin{array}{c}\mathbf{0 . 0 1 2} \\
(0.012) \\
\mathbf{0 . 8 3 6} \\
(0.773) \\
\mathbf{0 . 9 9 0 * *} \\
(0.465) \\
\mathbf{0 . 9 4 8 * * *} \\
(0.167)\end{array}$ & $\begin{array}{c}\mathbf{0 . 0 1 8} \\
(0.017) \\
\mathbf{0 . 9 2 0} \\
(0.782) \\
\mathbf{1 . 0 8 8 ^ { * * * }} \\
(0.446) \\
\mathbf{1 . 0 4 4 * *} \\
(0.162)\end{array}$ & $\begin{array}{c}\mathbf{0 . 0 2 6} \\
(0.022) \\
\mathbf{1 . 0 3 4}^{*} \\
(0.791) \\
\mathbf{1 . 2 0 9} * * * \\
(0.414) \\
\mathbf{1 . 1 2 6 * * *} \\
(0.149)\end{array}$ & $\begin{array}{c}\mathbf{0 . 0 3 5} \\
(0.029) \\
\mathbf{1 . 1 2 2}^{*} \\
(0.816) \\
\mathbf{1 . 3 0 2 * * *} \\
(0.410) \\
\mathbf{1 . 1 6 7 * * *} \\
(0.136)\end{array}$ \\
\hline & $\begin{array}{l}R^{2} \\
{\left[R_{L}^{2}, R_{H}^{2}\right]}\end{array}$ & $\begin{array}{c}0.07 \\
{[0.02,0.14]}\end{array}$ & $\begin{array}{c}0.15 \\
{[0.06,0.27]}\end{array}$ & $\begin{array}{c}0.20 \\
{[0.10,0.31]}\end{array}$ & $\begin{array}{c}0.24 \\
{[0.15,0.35]}\end{array}$ & $\begin{array}{c}0.30 \\
{[0.21,0.40]}\end{array}$ & $\begin{array}{c}0.35 \\
{[0.27,0.45]}\end{array}$ & $\begin{array}{c}0.38 \\
{[0.31,0.46]}\end{array}$ & $\begin{array}{c}0.43 \\
{[0.35,0.51]}\end{array}$ & $\begin{array}{c}0.45 \\
{[0.37,0.53]}\end{array}$ \\
\hline & $\begin{array}{l}\operatorname{Mean}\left(\mu_{t}\right) \\
\text { Std. Err. }\left(\mu_{t}\right)\end{array}$ & $\begin{array}{l}0.000 \\
0.031\end{array}$ & $\begin{array}{c}-0.000 \\
0.044\end{array}$ & $\begin{array}{c}-0.000 \\
0.054\end{array}$ & $\begin{array}{l}0.000 \\
0.062\end{array}$ & $\begin{array}{l}0.000 \\
0.068\end{array}$ & $\begin{array}{l}0.000 \\
0.073\end{array}$ & $\begin{array}{c}-0.000 \\
0.082\end{array}$ & $\begin{array}{c}-0.000 \\
0.088\end{array}$ & $\begin{array}{l}0.000 \\
0.095\end{array}$ \\
\hline
\end{tabular}


Table 7 (b): Components of Exchange Rate Model

\begin{tabular}{|c|c|c|c|c|c|c|c|c|c|c|}
\hline Horizon & & 1-month & 2-month & 3-month & 4-month & 5-month & 6-month & 8-month & 10-month & 12-month \\
\hline \multirow[t]{3}{*}{$\mathrm{CHF}$} & $\begin{array}{cc}\alpha & \\
& H . H . \\
\beta_{1} & \\
& \text { H.H. } \\
\beta_{2} & \\
& \text { H.H. } \\
\beta_{3} & \\
& \text { H.H. }\end{array}$ & $\begin{array}{c}\mathbf{0 . 0 0 2} \\
(0.002) \\
\mathbf{- 0 . 0 8 7} \\
(0.939) \\
\mathbf{1 . 5 6 3 * * *} \\
(0.648) \\
\mathbf{0 . 3 7 7 * * *} \\
(0.107)\end{array}$ & $\begin{array}{c}\mathbf{0 . 0 0 3} \\
(0.004) \\
\mathbf{0 . 0 3 7} \\
(0.867) \\
\mathbf{1 . 2 3 2}^{* *} \\
(0.569) \\
\mathbf{0 . 5 1 0 * * *} \\
(0.126)\end{array}$ & $\begin{array}{c}\mathbf{0 . 0 0 4} \\
(0.005) \\
\mathbf{0 . 0 7 7} \\
(0.719) \\
\mathbf{1 . 0 6 3}^{* *} \\
(0.496) \\
\mathbf{0 . 6 5 4} * * * \\
(0.139)\end{array}$ & $\begin{array}{c}\mathbf{0 . 0 0 5} \\
(0.005) \\
\mathbf{0 . 2 3 6} \\
(0.620) \\
\mathbf{1 . 0 1 7} * * \\
(0.482) \\
\mathbf{0 . 7 8 8 * * *} \\
(0.148)\end{array}$ & $\begin{array}{c}\mathbf{0 . 0 0 5} \\
(0.006) \\
\mathbf{0 . 3 2 0} \\
(0.593) \\
\mathbf{1 . 0 5 4} 4^{* * *} \\
(0.451) \\
\mathbf{0 . 8 4 5 * * *} \\
(0.148)\end{array}$ & $\begin{array}{c}\mathbf{0 . 0 0 6} \\
(0.007) \\
\mathbf{0 . 4 4 0} \\
(0.573) \\
\mathbf{1 . 0 8 1 * * *} \\
(0.425) \\
\mathbf{0 . 9 0 4 * * *} \\
(0.148)\end{array}$ & $\begin{array}{c}\mathbf{0 . 0 0 8} \\
(0.007) \\
\mathbf{0 . 5 6 4} \\
(0.501) \\
\mathbf{1 . 1 9 1 * * *} \\
(0.334) \\
\mathbf{0 . 9 0 9 * * *} \\
(0.157)\end{array}$ & $\begin{array}{c}\mathbf{0 . 0 1 0 *} \\
(0.007) \\
\mathbf{0 . 6 3 4} \\
(0.427) \\
\mathbf{1 . 2 0 2} * * * \\
(0.271) \\
\mathbf{0 . 9 4 4 * * *} \\
(0.152)\end{array}$ & $\begin{array}{c}\mathbf{0 . 0 1 1 *} \\
(0.008) \\
\mathbf{0 . 6 7 5} * \\
(0.437) \\
\mathbf{1 . 2 0 9 * * *} \\
(0.255) \\
\mathbf{0 . 9 9 2 * * *} \\
(0.144)\end{array}$ \\
\hline & $\begin{array}{l}R^{2} \\
{\left[R_{L}^{2}, R_{H}^{2}\right]}\end{array}$ & $\begin{array}{c}0.07 \\
{[0.03,0.13]}\end{array}$ & $\begin{array}{c}0.13 \\
{[0.08,0.20]}\end{array}$ & $\begin{array}{c}0.21 \\
{[0.15,0.28]}\end{array}$ & $\begin{array}{c}0.28 \\
{[0.21,0.36]}\end{array}$ & $\begin{array}{c}0.32 \\
{[0.26,0.40]}\end{array}$ & $\begin{array}{c}0.37 \\
{[0.31,0.45]}\end{array}$ & $\begin{array}{c}0.41 \\
{[0.34,0.49]}\end{array}$ & $\begin{array}{c}0.45 \\
{[0.38,0.51]}\end{array}$ & $\begin{array}{c}0.50 \\
{[0.44,0.56}\end{array}$ \\
\hline & $\begin{array}{l}\operatorname{Mean}\left(\mu_{t}\right) \\
\text { Std. Err. }\left(\mu_{t}\right)\end{array}$ & $\begin{array}{c}-0.000 \\
0.031\end{array}$ & $\begin{array}{l}0.000 \\
0.043\end{array}$ & $\begin{array}{c}-0.000 \\
0.050\end{array}$ & $\begin{array}{l}0.000 \\
0.056\end{array}$ & $\begin{array}{c}-0.000 \\
0.060\end{array}$ & $\begin{array}{c}-0.000 \\
0.062\end{array}$ & $\begin{array}{c}-0.000 \\
0.066\end{array}$ & $\begin{array}{c}-0.000 \\
0.070\end{array}$ & $\begin{array}{c}-0.000 \\
0.074\end{array}$ \\
\hline \multirow[t]{3}{*}{ GBP } & $\begin{array}{cc}\alpha & \\
& H . H . \\
\beta_{1} & \\
& \text { H.H. } \\
\beta_{2} & \\
& \text { H.H. } \\
\beta_{3} & \\
& \text { H.H. }\end{array}$ & $\begin{array}{c}-\mathbf{- 0 . 0 0 1} \\
(0.001) \\
\mathbf{0 . 0 7 6} \\
(1.449) \\
\mathbf{0 . 2 9 6} \\
(0.386) \\
\mathbf{0 . 6 4 0 * * *} \\
(0.145)\end{array}$ & $\begin{array}{c}\mathbf{- 0 . 0 0 1} \\
(0.003) \\
\mathbf{0 . 3 3 6} \\
(1.300) \\
\mathbf{0 . 5 3 5}^{*} \\
(0.360) \\
\mathbf{0 . 8 3 9 * * *} \\
(0.136)\end{array}$ & $\begin{array}{c}\mathbf{- 0 . 0 0 2} \\
(0.005) \\
\mathbf{0 . 2 1 9} \\
(1.286) \\
\mathbf{0 . 5 3 6}^{*} \\
(0.375) \\
\mathbf{0 . 9 0 9 * * *} \\
(0.141)\end{array}$ & $\begin{array}{c}\mathbf{- 0 . 0 0 3} \\
(0.006) \\
\mathbf{0 . 1 0 7} \\
(1.254) \\
\mathbf{0 . 5 3 9 *} \\
(0.410) \\
\mathbf{0 . 9 7 1 * * *} \\
(0.140)\end{array}$ & $\begin{array}{c}\mathbf{- 0 . 0 0 4} \\
(0.008) \\
\mathbf{0 . 1 2 3} \\
(1.199) \\
\mathbf{0 . 6 1 2}^{*} \\
(0.398) \\
\mathbf{1 . 0 0 9 * * *}^{*} \\
(0.143)\end{array}$ & $\begin{array}{c}\mathbf{- 0 . 0 0 4} \\
(0.009) \\
\mathbf{0 . 1 1 0} \\
(1.151) \\
\mathbf{0 . 6 3 7 * *} \\
(0.382) \\
\mathbf{1 . 0 0 9 * * *} \\
(0.140)\end{array}$ & $\begin{array}{c}\mathbf{- 0 . 0 0 6} \\
(0.011) \\
\mathbf{0 . 0 1 7} \\
(1.066) \\
\mathbf{0 . 6 0 5}^{*} \\
(0.371) \\
\mathbf{0 . 9 5 9 * * *} \\
(0.131)\end{array}$ & $\begin{array}{c}\mathbf{- 0 . 0 0 8} \\
(0.012) \\
\mathbf{- 0 . 0 9 2} \\
(0.977) \\
\mathbf{0 . 5 8 0 *} \\
(0.372) \\
\mathbf{0 . 9 3 3 * * *} \\
(0.124)\end{array}$ & $\begin{array}{c}\mathbf{- 0 . 0 1 0} \\
(0.014) \\
\mathbf{- 0 . 2 1 5} \\
(0.929) \\
\mathbf{0 . 5 5 4 *} \\
(0.387) \\
\mathbf{0 . 9 2 0 * * *} \\
(0.123)\end{array}$ \\
\hline & $\begin{array}{l}R^{2} \\
{\left[R_{L}^{2}, R_{H}^{2}\right]}\end{array}$ & $\begin{array}{c}0.14 \\
{[0.06,0.26]}\end{array}$ & $\begin{array}{c}0.27 \\
{[0.15,0.41]}\end{array}$ & $\begin{array}{c}0.33 \\
{[0.20,0.47]}\end{array}$ & $\begin{array}{c}0.38 \\
{[0.25,0.50]}\end{array}$ & $\begin{array}{c}0.42 \\
{[0.29,0.54]}\end{array}$ & $\begin{array}{c}0.44 \\
{[0.31,0.55]}\end{array}$ & $\begin{array}{c}0.44 \\
{[0.32,0.55]}\end{array}$ & $\begin{array}{c}0.48 \\
{[0.38,0.57]}\end{array}$ & $\begin{array}{c}0.52 \\
{[0.43,0.60}\end{array}$ \\
\hline & $\begin{array}{l}\operatorname{Mean}\left(\mu_{t}\right) \\
\text { Std. Err. }\left(\mu_{t}\right)\end{array}$ & $\begin{array}{c}-0.000 \\
0.025\end{array}$ & $\begin{array}{l}0.000 \\
0.034\end{array}$ & $\begin{array}{l}0.000 \\
0.041\end{array}$ & $\begin{array}{c}-0.000 \\
0.046\end{array}$ & $\begin{array}{l}0.000 \\
0.050\end{array}$ & $\begin{array}{c}-0.000 \\
0.054\end{array}$ & $\begin{array}{l}0.000 \\
0.061\end{array}$ & $\begin{array}{l}0.000 \\
0.063\end{array}$ & $\begin{array}{l}0.000 \\
0.065\end{array}$ \\
\hline
\end{tabular}

Notes: Estimates for $\Delta s_{t, t+k}^{o b s}=\alpha_{k}+\beta_{1, k} I R D_{t, t+k}+\beta_{2, k} R P_{t, t+k}+\beta_{3, k} F S D_{t, t+k}+\nu_{t+k}$, where $\Delta s_{t, t+k}^{o b s}$ is the observed log exchange rate change in USD between $t$ and $t+k$, the interest rate differential is $\operatorname{IRD} D_{t, t+k} \equiv \sum_{j=1}^{k}\left(r_{t+j-1}-r_{t+j-1}^{*}\right)$, the risk premium is

$R P_{t, t+k} \equiv \frac{1}{2} \sum_{j=1}^{k}\left(\Lambda_{t+j-1}^{\prime} \Lambda_{t+j-1}-\Lambda_{t+j-1}^{* \prime} \Lambda_{t+j-1}^{*}\right)$, and the factor shock differential is $F S D_{t, t+k} \equiv \sum_{j=1}^{k}\left(\Lambda_{t+j-1}^{\prime} \epsilon_{t+j}-\Lambda_{t+j-1}^{* \prime} \epsilon_{t+j}^{*}\right)$, where the domestic

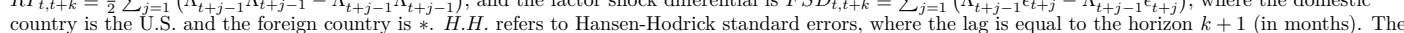
significance level of the coefficients is determined by $\left({ }^{*}\right)$ where ${ }^{* * *} \mathrm{p}<0.01,{ }^{* *} \mathrm{p}<0.05,{ }^{*} \mathrm{p}<0.1 . R^{2}$ is adjusted for degrees of freedom and $\left[R_{L}^{2}, R_{H}^{2}\right]$ indicates the simulation-based (5,000 bootstrap) $95 \%$ confidence interval for the $R^{2}$

The RP and FSD components seem to be the most important terms in explaining exchange rate movements for all currencies; $\beta_{2}$ and $\beta_{3}$ are usually positive, large, and statistically significant, with some exceptions such as for the CAD/USD exchange rate fluctuations. In most cases, the null hypothesis that $H_{0}$ : $\beta_{2}=1$ cannot be rejected, whereas the hypothesis that $H_{0}: \beta_{3}=1$ cannot be rejected for longer horizons, but is typically rejected at short (1-month to 3-month) horizons (except for the GBP). Other statistical tests analyzing these relationships can be found in the Appendix.

Interest rate risk priced in both countries' yield curves through the factors accounts for fluctuations in the exchange rate in different ways. While the IRD relates to currency returns linearly, the RP term captures higher moments of the SDFs that govern the path of the exchange rate. Additionally, the FSD component exposes the exchange rate to interest rate shocks, which become mitigated/amplified by the degree of risk aversion of investors in both countries $\left(\Lambda_{t}, \Lambda_{t}^{*}\right)$.

On a final note, notice from equation (7) that the non-linearities in the exchange rate are dictated by the shape of the SDF. Other SDF specifications under a new set of assumptions might lead to a different relationship. In particular, previous work has focused on multi-factor extensions of the Cox et al. (1985) model, which yield a risk premium that is linear in the factors. Although affine models are more convenient 
to work with, the non-linearities implied by the Gaussian distribution of the SDFs are consistent with optimal trading behavior.

Consider a portfolio manager who decides to allocate her wealth across a portfolio of bonds with different terms to maturity. As the interest rate factors (level, slope, and curvature) vary, she reallocates her wealth to maximize profits under the assumption that the expected returns on these bonds have a mean-reverting property that stems from the autoregressive process of the factors. Chami et al. (2017) show that for a risk-averse trader with constant relative risk aversion, if the factors are to the right of the conditional mean of the SDF, the SDF is expected to increase towards the peak of the distribution, and vice-versa. Thus, the trader experiences capital gains when the factors revert back to their mean, but losses when the factors move away from the mean. Given that both countries' yield curves move cross-sectionally and over time and all the factors are influencing the path of the exchange rate simultaneously, we would expect different net effects on the exchange rate depending on where the factors are relative to the conditional means of the Gaussian SDFs of the investors, leading to non-linearities in the relationship.

Although this analysis remains agnostic on the macroeconomic source of shocks that affect the exchange rate, through the interest rate factors one can study the effect of broader movements in the yield curve, in terms of the level shifts, changes in the slope, and the convexity of the term structure. The implied non-linearities established in this framework explain why similar changes in interest rates can have opposite effects in the exchange rate, given the pronounced asymmetries that arise from Gaussian distributions of investors' pricing kernels.

In summary, the failure of UIP can be explained by the RP component, which depends on the countries' SDF conditional volatilities and is consistent with the Fama conditions for the exchange-rate risk premium. Moreover, the implied non-linearities are important because movements in the entire yield curve influence exchange rate fluctuations depending on the original shape of the yield curve, i.e., where the factors are relative to the conditional mean of the SDF distributions.

\section{Conclusion}

Given that a representative investor in a particular country has the opportunity to buy alternative assets, the same SDF that prices bond returns should also be able to price other financial assets, such as the exchange rate. The failure of UIP, the fact that the difference between domestic and foreign interest rates has a negative impact on the change in the exchange rates, can be associated with the differences in risk premium across countries. To examine UIP, this paper uses the well-known result under complete markets and no arbitrage that currency returns are contemporaneously determined by the ratio of the domestic and foreign 
SDFs and unveils a non-linear risk premium that captures higher moments of the SDFs.

In this framework, interest rate factors -level, slope, and curvature, are shown to account for half of the variation in one-year currency returns for different countries during the 1980s-2016 period. Through these factors, movements across the entire maturity spectrum of the yield curve in different countries influence the path of the exchange rate, non-linearly, depending on where they are relative to the conditional mean of the distribution of the SDFs. These non-linearities are consistent with optimal portfolio theory and might be more important in determining exchange rate fluctuations than previously thought.

This paper advances our understanding of theoretical and empirical connections between the term structure of interest rates and exchange rates, yet many questions prevail. Since a large fraction of exchange rate fluctuations remains unexplained by interest-rate risk, as found in the literature on excess volatility of exchange rates, there seems to be substantial variation in exchange rates that is orthogonal to the cross-section of interest rates, particularly in the short run. Developing a general equilibrium framework with a Gaussian SDF and short- and long-term bonds that can also account for the impact of macroeconomic shocks on the yield curve and the exchange rate would help to provide a comprehensive insight into these relationships. 


\section{References}

Ang, A. and Chen, J. (2010). Yield Curve Predictors of Foreign Exchange Returns. Working Paper.

Backus, D. K., Foresi, S., and Telmer, C. I. (2001). Affine Term Structure Models and the Forward Premium Anomaly. Journal of Finance, 56(1):279-304.

Bauer, G. H. and Diez de los Rios, A. (2012). An International Dynamic Term Structure Model with Economic Restrictions and Unspanned Risks. Bank of Canada Working Paper 2012-5.

Bauer, M. D. and Hamilton, J. D. (2016). Robust Bond Risk Premia. Working Paper.

Bauer, M. D. and Rudebusch, G. D. (2016). Resolving the Spanning Puzzle in Macro-Finance Term Structure Models. Review of Finance, forthcoming.

Bauer, M. D., Rudebusch, G. D., and Wu, J. C. (2012). Correcting Estimation Bias in Dynamic Term Structure Models. Journal of Business 83 Economic Statistics, 30(3):454-467.

Bauer, M. D., Rudebusch, G. D., and Wu, J. C. (2014). Term Premia and Inflation Uncertainty: Empirical Evidence from an International Panel Dataset: Comment. American Economic Review, 104(1):323-337.

Bekaert, G. (1996). The Time Variation of Risk and Return in Foreign Exchange Markets: A General Equilibrium Perspective. Review of Financial Studies, 9(2):427-470.

Benati, L. (2006). Affine Term Structure Models for the Foreign Exchange Risk Premium. Bank of England Working Paper No. 291.

Brandt, M. W. and Santa-Clara, P. (2002). Simulated Likelihood Estimation of Diffusions with an Application to Exchange Rate Dynamics in Incomplete Markets. Journal of Financial Economics, 63(2):161-210.

Brennan, M. J. and Xia, Y. (2006). International Capital Markets and Foreign Exchange Risk. Review of Financial Studies, 19(3):753-795.

Burnside, C., Eichenbaum, M., Kleshchelski, I., and Rebelo, S. (2011). Do Peso Problems Explain the Returns to the Carry Trade? Review of Financial Studies, 24(3):853-891.

Campbell, J. Y. and Shiller, R. J. (1991). Yield Spreads and Interest Rate Movements: A Bird's Eye View. Review of Economic Studies, 58(3):495-514.

Cenedese, G., Sarno, L., and Tsiakas, I. (2014). Foreign Exchange Risk and the Predictability of Carry Trade Returns. Journal of Banking 83 Finance, 42:302-313. 
Chabi-Yo, F. and Yang, J. (2007). A No-Arbitrage Analysis of Macroeconomic Determinants of Term Structures and the Exchange Rate. Bank of Canada Working Paper 2007-21.

Chami, R., Cosimano, T. F., Ma, J., and Rochon, C. (2017). What's Different About Bank Holding Companies? IMF Working Paper No. 17/26.

Chen, Y.-c. and Tsang, K. P. (2013). What Does the Yield Curve Tell Us about Exchange Rate Predictability? Review of Economics and Statistics, 95(1):185-205.

Chinn, M. D. and Meredith, G. (2004). Monetary Policy and Long-Horizon Uncovered Interest Parity. IMF Staff Papers, 51(3):409-430.

Clarida, R. H., Sarno, L., Taylor, M. P., and Valente, G. (2003). The Out-of-Sample Success of Term Structure Models as Exchange Rate Predictors: A Step Beyond. Journal of International Economics, $60(1): 61-83$.

Clarida, R. H. and Taylor, M. P. (1997). The Term Structure of Forward Exchange Premiums and the Forecastability of Spot Exchange Rates: Correcting the Errors. Review of Economics and Statistics, $79(3): 353-361$.

Cochrane, J. H. (2008). The Dog that Did not Bark: A Defense of Return Predictability. Review of Financial Studies, 21(4):1533-1575.

Cochrane, J. H. (2011). Presidential Address: Discount Rates. Journal of Finance, 66(4):1047-1108.

Cox, J. C., Ingersoll, J. E. J., and Ross, S. A. (1985). A Theory of the Term Structure of Interest Rates. Econometrica, 53(2):385-407.

Dai, Q. and Singleton, K. J. (2000). Specification Analysis of Affine Term Structure Models. Journal of Finance, 55(5):1943-1978.

Dai, Q. and Singleton, K. J. (2002). Expectation Puzzles, Time-Varying Risk Premia, and Affine Models of the Term Structure. Journal of Financial Economics, 63:415-441.

Dai, Q. and Singleton, K. J. (2003). Term Structure Dynamics in Theory and Reality. Review of Financial Studies, 16(3):631-678.

Diebold, F. X., Piazzesi, M., and Rudebusch, G. D. (2005). Modeling Bond Yields in Finance and Macroeconomics. American Economic Review PEYP, 95(2):415-420. 
Diez de los Rios, A. (2009). Can Affine Term Structure Models Help Us Predict Exchange Rates? Journal of Money, Credit and Banking, 41(4):755-766.

Dong, S. (2006). Macro Variables Do Drive Exchange Rate Movements: Evidence from a No-Arbitrage Model. SSRN Working Paper 890873.

Duffee, G. (2002). Term Premia and Interest Rate Forecasts in Affine Models. Journal of Finance, 57:405433.

Duffie, D. and Kan, R. (1996). A Yield-Factor Model of Interest Rates. Mathematical Finance, 6(4):379-406.

Evans, C. L. and Marshall, D. A. (1998). Monetary Policy and the Term Structure of Nominal Interest Rates: Evidence and Theory. In Carnegie-Rochester Conference Series on Public Policy, volume 49, pages $53-111$.

Evans, C. L. and Marshall, D. A. (2007). Economic Determinants of the Nominal Treasury Yield Curve. Journal of Monetary Economics, 54(7):1986-2003.

Fama, E. F. (1984). Forward and Spot Exchange Rates. Journal of Monetary Economics, 14(3):319-338.

Fama, E. F. and Bliss, R. R. (1987). The Information in Long-Maturity Forward Rates. American Economic Review, 77(4):680-692.

Fama, E. F. and French, K. R. (1988). Dividend Yields and Expected Stock Returns. Journal of Financial Economics, 22(1):3-25.

Frachot, A. (1996). A Reexamination of the Uncovered Interest Rate Parity Hypothesis. Journal of International Money and Finance, 15(3):419-437.

Froot, K. and Thaler, R. (1990). Anomalies: Foreign Exchange. Journal of Economic Perspectives, 4(3):179192.

Gürkaynak, R. S. and Wright, J. H. (2012). Macroeconomics and the Term Structure. Journal of Economic Literature, 50(2):331-367.

Hansen, L. P. and Hodrick, R. J. (1980). Forward Exchange Rates as Optimal Predictors of Future Spot Rates: An Econometric Analysis. Journal of Political Economy, 88(5):829-853.

Imbs, J., Mumtaz, H., Ravn, M. O., and Rey, H. (2003). Nonlinearities and Real Exchange Rate Dynamics. Journal of the European Economic Association, 1(2-3):639-649. 
Inci, A. C. and Lu, B. (2004). Exchange Rates and Interest Rates: Can Term Structure Models Explain Currency Movements? Journal of Economic Dynamics and Control, 28(8):1595-1624.

Joslin, S., Le, A., and Singleton, K. J. (2013). Why Gaussian Macro-Finance Term Structure Models Are (Nearly) Unconstrained Factor-VARs. Journal of Financial Economics, 109:604-622.

Joslin, S., Priebsch, M., and Singleton, K. J. (2014). Risk Premiums in Dynamic Term Structure Models with Unspanned Macro Risks. Journal of Finance, 69(3):1197-1233.

Joslin, S., Singleton, K. J., and Zhu, H. (2011). A New Perspective on Gaussian Dynamic Term Structure Models. Review of Financial Studies, 24(3):926-970.

Lewis, K. (1995). Puzzles in International Financial Markets. In Grossman, G. and Rogoff, K., editors, Handbook of International Economics. North Holland: Amsterdam.

Litterman, R. B. and Scheinkman, J. (1991). Common Factors Affecting Bond Returns. Journal of Fixed Income, 1(1):54-61.

Lustig, H., Roussanov, N., and Verdelhan, A. (2011). Common Risk Factors in Currency Markets. Review of Financial Studies, 24(11):3731-3777.

Lustig, H., Roussanov, N., and Verdelhan, A. (2014). Countercyclical Currency Risk Premia. Journal of Financial Economics, 111(3):527-553.

Lustig, H., Stathopoulos, A., and Verdelhan, A. (2015). Nominal Exchange Rate Stationarity and Long-Term Bond Returns. SSRN Working Paper 2340547.

Lustig, H. and Verdelhan, A. (2007). The Cross Section of Foreign Currency Risk Premia and Consumption Growth Risk. American Economic Review, 97(1):89-117.

Mark, N. C. (1995). Exchange Rates and Fundamentals: Evidence on Long-Horizon Predictability. American Economic Review, 85(1):201-218.

Meese, R. A. and Rogoff, K. (1983). Empirical Exchange Rate Models of the Seventies: Do They Fit Out of Sample? Journal of International Economics, 14(1-2):3-24.

Menkhoff, L., Sarno, L., Schmeling, M., and Schrimpf, A. (2012). Carry Trades and Global Foreign Exchange Volatility. Journal of Finance, 67(2):681-718.

Pericoli, M. and Taboga, M. (2012). Bond Risk Premia, Macroeconomic Fundamentals and the Exchange Rate. International Review of Economics \& Finance, 22(1):42-65. 
Piazzesi, M. (2010). Affine Term Structure Models. In Handbook of Financial Econometrics, volume 12, pages 691-766. Elsevier.

Piazzesi, M. and Schneider, M. (2007). Equilibrium Yield Curves. In NBER Macroeconomics Annual 2006, Volume 21, pages 389-472. MIT Press.

Sarno, L., Schneider, P., and Wagner, C. (2012). Properties of Foreign Exchange Risk Premiums. Journal of Financial Economics, 105(2):279-310.

Sarno, L., Taylor, M. P., and Chowdhuryd, I. (2004). Nonlinear Dynamics in Deviations from the Law of One Price: A Broad-Based Empirical Study. Journal of International Money and Finance, 23(1):1-25.

Singleton, K. J. (2009). Empirical Dynamic Asset Pricing: Model Specification and Econometric Assessment. Princeton University Press.

Taylor, M. P., Peel, D. A., and Sarno, L. (2001). Nonlinear Mean-Reversion in Real Exchange Rates: Toward a Solution To the Purchasing Power Parity Puzzles. International Economic Review, 42(4):1015-1042.

Vasicek, O. (1977). An Equilibrium Characterization of the Term Structure. Journal of Financial Economics, $5(2): 177-188$

Verdelhan, A. (2015). The Share of Systematic Variation in Bilateral Exchange Rates. Journal of Finance, forthcoming.

Wu, T. (2006). Macro Factors and the Affine Term Structure of Interest Rates. Journal of Money, Credit and Banking, 38(7):1847-1875.

Yin, W. and Li, J. (2014). Macroeconomic Fundamentals and the Exchange Rate Dynamics: A No-Arbitrage Macro-Finance Approach. Journal of International Money and Finance, 41:46-64. 